OPEN ACCESS

Edited by:

Vincenza Cifarelli,

Washington University in St. Louis,

United States

Reviewed by:

Joseph M. Rutkowski,

Texas A\&M University College of Medicine, United States

Beth Ann Tamburini,

University of Colorado Denver,

United States

*Correspondence:

Pieter R. Norden

pieter.norden@northwestern.edu

Tsutomu Kume

t-kume@northwestern.edu

Specialty section:

This article was submitted to

Lipid and Fatty Acid Research,

a section of the journal

Frontiers in Physiology

Received: 30 January 2020

Accepted: 06 April 2020

Published: 05 May 2020

Citation:

Norden PR and Kume T (2020) The Role of Lymphatic Vascular

Function in Metabolic Disorders.

Front. Physiol. 11:404.

doi: 10.3389/fphys.2020.00404

\section{The Role of Lymphatic Vascular Function in Metabolic Disorders}

\author{
Pieter R. Norden* and Tsutomu Kume* \\ Feinberg Cardiovascular and Renal Research Institute, Department of Medicine, Feinberg School of Medicine, Northwestern \\ University, Chicago, IL, United States
}

In addition to its roles in the maintenance of interstitial fluid homeostasis and immunosurveillance, the lymphatic system has a critical role in regulating transport of dietary lipids to the blood circulation. Recent work within the past two decades has identified an important relationship between lymphatic dysfunction and patients with metabolic disorders, such as obesity and type 2 diabetes, in part characterized by abnormal lipid metabolism and transport. Utilization of several genetic mouse models, as well as non-genetic models of diet-induced obesity and metabolic syndrome, has demonstrated that abnormal lymphangiogenesis and poor collecting vessel function, characterized by impaired contractile ability and perturbed barrier integrity, underlie lymphatic dysfunction relating to obesity, diabetes, and metabolic syndrome. Despite the progress made by these models, the contribution of the lymphatic system to metabolic disorders remains understudied and new insights into molecular signaling mechanisms involved are continuously developing. Here, we review the current knowledge related to molecular mechanisms resulting in impaired lymphatic function within the context of obesity and diabetes. We discuss the role of inflammation, transcription factor signaling, vascular endothelial growth factor-mediated signaling, and nitric oxide signaling contributing to impaired lymphangiogenesis and perturbed lymphatic endothelial cell barrier integrity, valve function, and contractile ability in collecting vessels as well as their viability as therapeutic targets to correct lymphatic dysfunction and improve metabolic syndromes.

\footnotetext{
Keywords: obesity, lymphatic, inflammation, nitrous oxide, vascular endothelial growth factors, transcription factor, metabolic syndrome
}

\section{INTRODUCTION}

The growing epidemic of obesity is characterized predominately by the accumulation of excess adipose tissue, which is due to an array of causes including the transition to an increasingly sedentary lifestyle and diets containing processed foods high in calorie content. The progression of this epidemic presents a major challenge to chronic disease prevention, including predisposal to the development of disability, depression, certain cancers, type 2 diabetes (T2D), metabolic syndrome, and cardiovascular disease (Grundy, 2004; De Pergola and Silvestris, 2013; Hruby and Hu, 2015; O'Neill and O'Driscoll, 2015; Ortega et al., 2016). In the United States, severe estimates predict that $86.3 \%$ of adults will be overweight or obese by 2030 (Wang et al., 2008), thus underscoring the critical need for development of novel therapeutic treatments in addition to preventative measures and lifestyle changes. Emerging evidence generated within the past 
two decades has identified key mechanisms relating lymphatic vascular dysfunction with the pathogenesis of obesity, T2D, abnormal lipid metabolism and metabolic syndrome. In particular, the development and progression of metabolic syndrome, obesity, and T2D in some cases is associated with abnormal lymphangiogenesis and impaired function of collecting vessels during lipid transport and immune surveillance (Harvey, 2008; Dixon, 2010; Scallan et al., 2016; Escobedo and Oliver, 2017; Cifarelli and Eichmann, 2019). This review summarizes our current knowledge of the mechanisms by which lymphatic dysfunction contributes to pathogenesis of obesity, diabetes, and metabolic syndrome; focusing on the role of inflammation, transcription factors, vascular endothelial growth factor (VEGF)-signaling and nitric oxide (NO) signaling. Additionally, we discuss recent therapeutic developments targeting lymphatic function for the treatment of diabetes, obesity, and metabolic syndrome.

\section{THE LYMPHATIC VASCULAR SYSTEM}

Unlike the closed blood circulatory system, the lymphatic system consists of a blind-ended, unidirectional network of absorptive vessels and secondary lymphoid organs, which include lymph nodes, spleen, Peyer's patches, adenoids, and tonsils, in which lymph collected from the interstitial space is eventually drained into the blood vasculature via transport through the thoracic duct into the subclavian vein (Ruddle and Akirav, 2009; Choi et al., 2012). This unidirectional transport mechanism serves to support the critical physiological roles of the lymphatic vasculature in maintaining interstitial fluid and protein homeostasis, developing an immune surveillance response by transporting antigen and antigen-presenting cells to lymph nodes, and facilitating the uptake of vitamins and dietary lipids, transported by lipoprotein particles known as chylomicrons, into the mesenteric lymphatic vessels from the digestive tract via the intestinal lacteals (Schulte-Merker et al., 2011; Randolph et al., 2017; Santambrogio, 2018; Cifarelli and Eichmann, 2019). During lymph formation, interstitial fluid containing water, solutes, and immune cells is initially transported into the lumen of highly permeable lymphatic capillary vessels. These vessels consist of lymphatic endothelial cells (LECs) arranged in an oak-leaf pattern characterized with discontinuous, overlapping, "button-like" cell-cell junctions (Baluk et al., 2007). Hydrostatic pressure gradients acting across the lymphatic wall facilitate the opening or closure of these overlapping cell-cell junctions, thus functioning as a primary valve system (Schmid-Schonbein, 2003). Additionally, capillary LECs are also directly attached to the extracellular matrix (ECM) by anchoring filaments (Leak and Burke, 1968). High interstitial fluid pressure also facilitates the opening of overlapping junctions by stretching these anchoring filaments to promote the transport of interstitial fluid into the capillary lumen. Increased intraluminal pressure then promotes the closure of overlapping junctions to inhibit lymph leakage (Schmid-Schonbein, 2003; Sabine et al., 2016). Lymph formed in the capillaries is then passively transported to collecting vessels where LECs are arranged into contractile segments, known as lymphangions, which are separated by intraluminal, bi-leaflet lymphatic valves. These lymphangion regions are additionally coated by basement membrane and lymphatic muscle cells (Muthuchamy et al., 2003). In contrast to the lymphatic capillaries, LECs in collecting vessels form continuous "zipper-like" cell-cell junctions to prevent lymph-leakage during transport (Sabine et al., 2016). Coordination of several forces then promotes the propulsion of lymph within the collecting vessels and maintenance of unidirectional transport. This includes both intrinsic pump forces, derived from contraction of lymphatic muscle and extrinsic forces generated from surrounding tissues (e.g., respiration and contraction of cardiac and skeletal muscle). Additionally, regulation of the opening and closure of intraluminal valves supports unidirectional transport of lymph and prevents backflow. Increases in luminal lymph pressure within lymphangions drives the closure of valve leaflets as they are pushed together. As lymph pressure continues to increase within the lymphangion, the lymphatic endothelium stretches and activates the lymphatic pump, which opens valves to transport lymph to sequential lymphangions (Zawieja, 2009; Bertram et al., 2011; Sabine et al., 2016).

During murine embryonic development, formation of the early lymphatic vascular system is initiated at embryonic day (E) 9.5 as a subset of endothelial cells in the cardinal vein begin to express the Prospero-related homeobox 1 (PROX1) transcription factor, that acts as a master lymphatic regulator. These cells then differentiate into LECs, and migrate to establish primitive lymphatic vessels, identified as the jugular lymph sac, by E11.5 (Wigle and Oliver, 1999). However, more recent evidence has also demonstrated the contribution of other tissue-associated vascular progenitor cells as well as non-endothelial cells to early lymphatic vasculature morphogenesis and the development of the primitive lymphatic vascular network (Bernier-Latmani et al., 2015; Klotz et al., 2015; Martinez-Corral et al., 2015; Stanczuk et al., 2015; Kazenwadel and Harvey, 2016). Several critical signaling pathways are involved in this process including VEGF-C/-D activation of the VEGFR-3 receptor tyrosine kinase, regulation of key downstream gene expression by SOX18, PROX1, GATA2, and FOXC2 transcription factors, as well as Notch1, FGF2/FGFR1, ANG2/TIE2, and EFNB2/EPHB4 signaling, which have been previously reviewed in great detail in articles we refer to the reader (Tammela and Alitalo, 2010; Schulte-Merker et al., 2011; Yang and Oliver, 2014; Zheng et al., 2014). We discuss the progression of metabolic syndrome derived from lymphatic dysfunction as a result of impaired signaling in several of the pathways mentioned, and in contrast the effect of chronic inflammation derived from obesity and metabolic syndrome on several of these signaling pathways, resulting in lymphatic dysfunction, in greater detail below.

\section{THE RELATIONSHIP OF METABOLIC SYNDROME, INFLAMMATION, AND LYMPHATIC DYSFUNCTION}

Numerous studies have demonstrated a role for obesity in the induction of a chronic low-grade inflammatory response 
(Lumeng and Saltiel, 2011; Saltiel and Olefsky, 2017). In human obese and T2D patients, evidence has shown that several inflammatory markers are elevated, including white blood cell counts and plasma levels of coagulation factors (PAI-1 and fibrinogen), acute-phase proteins (C-reactive protein and serum amyloid A), pro-inflammatory cytokines (tumor necrosis factor (TNF)- $\alpha$, interleukin (IL)-1 $\beta$, and IL-6), as well as proinflammatory chemokines (Pickup et al., 1997; Yudkin et al., 1999; Bastard et al., 2000; Haffner et al., 2005; Bruun et al., 2006; Belalcazar et al., 2013; Esser et al., 2014). Furthermore, in most cases increases in these pro-inflammatory markers also positively correlated with insulin resistance and metabolic syndrome independent of the degree of obesity (Esser et al., 2014). Both clinical data and experimental data from mouse models have demonstrated that liver, muscle, pancreas, and adipose tissue are sites of both ectopic lipid deposition (in non-adipose tissues) (Mittendorfer, 2011; Snel et al., 2012) and inflammation present in metabolic syndrome including obesity, T2D, and non-alcoholic steatohepatitis (NASH) as a result of infiltration of pro-inflammatory macrophages, which secrete proinflammatory cytokines such as TNF- $\alpha$, IL-1 $\beta$, and IL-6 into these tissues (Chawla et al., 2011; Walenbergh et al., 2013; Esser et al., 2014; Martin-Murphy et al., 2014; McGettigan et al., 2019). During obesity, the adipose tissue in particular has been associated with an accumulation of immune cells in its stromovascular fraction (Chawla et al., 2011) and importantly, increased intra-abdominal visceral fat accumulation is more strongly correlated with metabolic syndrome compared to subcutaneous fat accumulation, suggesting that the pathogenic role of adipose tissue is related to its anatomic location (Koster et al., 2010; Esser et al., 2014). Of critical importance, several clinical studies within the past three decades have demonstrated that obesity and elevated body mass index (BMI) presents a significant risk to lymphatic dysfunction, particularly to female breast cancer patients who are at risk for the development of lymphedema postoperatively (Werner et al., 1991; Meek, 1998; Petrek et al., 2001; Johansson et al., 2002; Meric et al., 2002; Goffman et al., 2004; Ozaslan and Kuru, 2004; Clark et al., 2005; Wilke et al., 2006; McLaughlin et al., 2008; Swenson et al., 2009; Helyer et al., 2010; Vasileiou et al., 2011; Greene et al., 2012; Paskett et al., 2012). Moreover, clinical studies utilizing non-invasive imaging techniques such as near-infrared lymphatic imaging, magnetic resonance imaging, and bioimpedance spectroscopy have characterized lymphatic dysfunction associated with diseases characterized by abnormal adipose tissue accumulation in addition to obesity, such as lipedema and Dercum's disease (Lohrmann et al., 2009; Rasmussen et al., 2014; Sevick-Muraca et al., 2014; Crescenzi et al., 2018; Crescenzi et al., 2019). Numerous studies within the past two decades using both genetic and diet-manipulated mouse models have now identified key mechanisms underlying the cross-talk of obesity, diabetes, NASH, and metabolic syndrome with lymphatic vascular dysfunction (Table 1), of which several models are discussed in additional detail in this review.

Several studies utilizing non-genetic, diet-induced obesity mouse models, in which WT mice have been fed a prolonged high-fat diet compared to control WT mice that are fed normal chow, have demonstrated that increased inflammation induced in obese mice is associated with impaired lymphatic function (Savetsky et al., 2014; García Nores et al., 2016; Hespe et al., 2016; Nitti et al., 2016). Diet-induced obesity in mice was shown to impair lymphatic function as uptake of ${ }^{99 \mathrm{~m}} \mathrm{Tc}$-labeled sulfur colloid into sacral lymph nodes after tail injections was decreased in obese mice compared to lean controls and this was exacerbated in obese mice exhibiting lymphedema after surgical tail lymphatic excision. In subcutaneous tissue of the mouse tail, $\mathrm{CD}^{+}$cell infiltration was significantly increased in obese mice at baseline and the presence of lymphedema in obese mice greatly increased both $\mathrm{CD} 45^{+}$ and $\mathrm{CD}^{+}$cell infiltration as well as subcutaneous adipose deposition (Savetsky et al., 2014). Importantly, evidence has shown that impaired lymphatic function and reduced lymphatic density in obese mice is associated with obesityinduced perilymphatic accumulation of inflammatory cells, such as $\mathrm{CD}^{+} \mathrm{T}$ cells and $\mathrm{CD} 11 \mathrm{~b}^{+}$macrophages, and toxic lipid by-products contributing to the chronic inflammatory environment. Furthermore, comparison of obesity-prone and obesity-resistant mice fed a prolonged high-fat diet demonstrated that dietary changes alone were not sufficient to induce lymphatic dysfunction, thus underscoring the role of obesity-induced inflammation in lymphatic dysfunction (García Nores et al., 2016).

The observation that increased inflammation associated with obesity is correlated with lymphatic dysfunction and reduced vessel density may seem contradictory provided that several studies have shown that under an inflammatory environment, lymphangiogenesis is stimulated as a mechanism for antigen clearance and inflammation resolution in response to prolymphangiogenic factors, such as VEGF-C, VEGF-D, and VEGF$A$, that are secreted from infiltrating macrophages that respond to chemoattractants expressed by LECs (Kataru et al., 2009; Rahier et al., 2011; Kim et al., 2014). However, other studies have demonstrated that anti-lymphangiogenic cytokines, including IFN- $\gamma$ and TGF- $\beta 1$ (Shao and Liu, 2006; Clavin et al., 2008; Oka et al., 2008; Kataru et al., 2011), are elevated in chronic inflammatory responses (Zampell et al., 2012b; Savetsky et al., 2015b; Shin et al., 2015; Kataru et al., 2019) and elevated IFN- $\gamma$ and TGF- $\beta 1$ levels were previously detected in obese mice (Winer et al., 2009; Hespe et al., 2016). Additionally, elevated TGF- $\beta 1$ levels and BMI were observed to have significant partial correlation in human subjects (Yadav et al., 2011). A key observation in studies utilizing both mouse and rat models of obesity and metabolic syndrome is that the lymphatic vessels are leaky and collecting vessel contraction is impaired in subcutaneous and mesenteric collecting vessels (Zawieja et al., 2012; Weitman et al., 2013; Blum et al., 2014; Savetsky et al., 2014, 2015a; García Nores et al., 2016; Hespe et al., 2016; Nitti et al., 2016). While the specific mechanism of lymphatic leakiness in obesity is unclear at this time, it has been proposed that increased perilymphatic accumulation of inflammatory cells, increased production of inflammatory cytokines, and the observation that perilymphatic inducible nitric oxide synthase (iNOS) expression is increased in obese mice may contribute to this phenotype (Hespe 
TABLE 1 | Genetic and diet-induced animal models relating obesity, diabetes, and metabolic syndrome with lymphatic dysfunction.

\begin{tabular}{|c|c|c|c|}
\hline Animal model & Definition & Metabolic and lymphatic phenotypes & References \\
\hline Ldlr $r^{-/-}$ & $\begin{array}{l}\text { Deficiency of low-density lipoprotein } \\
\text { receptor }\end{array}$ & $\begin{array}{l}\text { - Prone to accelerated atherosclerosis progression with } \\
\text { incorporation of a high-fat diet } \\
\text { - Pre-treatment with VEGF-C } 152 S \text { before incorporation of } \\
\text { a pro-atherosclerotic diet regimen stimulates } \\
\text { lymphangiogenesis of initial vessels, improves lymphatic } \\
\text { collecting vessel transport and contractile frequency, and } \\
\text { reduces inflammatory cell accumulation }\end{array}$ & $\begin{array}{l}\text { Daugherty et al., 2017; } \\
\text { Milasan et al., } 2019\end{array}$ \\
\hline APN-KO mice & $\begin{array}{l}\text { Deficiency of adipose-specific plasma } \\
\text { adipokine adiponectin, which is } \\
\text { down-regulated in association with } \\
\text { various obesity-related diseases }\end{array}$ & $\begin{array}{l}\text { - Development of insulin resistance and neointimal } \\
\text { formation } \\
\text { - Greater susceptibility to microsurgically induced } \\
\text { lymphedema associated with reduced lymphatic vascular } \\
\text { density }\end{array}$ & $\begin{array}{l}\text { Kubota et al., 2002; } \\
\text { Shimizu et al., } 2013\end{array}$ \\
\hline Chy mutant mice & $\begin{array}{l}\text { Heterozygous inactivating mutation in } \\
\text { Vegfr3 }\end{array}$ & $\begin{array}{l}\text { - Characterized by defective lymphatic vessels and } \\
\text { appearance of chylous ascites } \\
\text { - Display abnormal subcutaneous adipose deposition in the } \\
\text { edematous subcutaneous adipose layer } \\
\text { - Have increased tissue lipid and collagen content in the } \\
\text { skin }\end{array}$ & $\begin{array}{l}\text { Karkkainen et al., 2001; } \\
\text { Rutkowski et al., } 2010\end{array}$ \\
\hline $\begin{array}{l}\text { K14-VEGFR-3-Ig } \\
\text { mice }\end{array}$ & $\begin{array}{l}\text { Express a soluble, ligand-binding } \\
\text { extracellular portion of VEGFR-3 in the } \\
\text { mouse epidermis under the keratin } 14 \\
\text { (K14) promoter }\end{array}$ & $\begin{array}{l}\text { - Inhibits dermal lymphatic vessel formation and } \\
\text { lymphangiogenesis and exhibits Iymphedema phenotype in } \\
\text { limbs } \\
\text { - As opposed to Chy mice with a similar lack of dermal } \\
\text { lymphatics, heterozygous K14-VEGFR-3-Ig mice did not } \\
\text { display abnormal collagen or lipid deposition } \\
\text { - Protected against high-fat diet-induced obesity and } \\
\text { improved systemic insulin sensitivity by suppressing } \\
\text { infiltration of pro-inflammatory macrophages via scavenging } \\
\text { of VEGF-C and VEGF-D }\end{array}$ & $\begin{array}{l}\text { Makinen et al., 2001; } \\
\text { Rutkowski et al., 2010; } \\
\text { Karaman et al., } 2015\end{array}$ \\
\hline
\end{tabular}


TABLE 1 | Continued

\begin{tabular}{|c|c|c|c|}
\hline Animal model & Definition & Metabolic and lymphatic phenotypes & References \\
\hline $\begin{array}{l}\text { High-fat } \\
\text { diet-induced } \\
\text { obesity }\end{array}$ & $\begin{array}{l}\text { Increased weight gain and progression } \\
\text { to obesity by incorporation of a larger } \\
\text { percentage of calories acquired from } \\
\text { fats }\end{array}$ & $\begin{array}{l}\text { - Development of insulin resistance, impaired glucose } \\
\text { tolerance, dyslipidemia, ectopic lipid accumulation, hepatic } \\
\text { steatosis } \\
\text { - Decreased lymphatic pumping frequency } \\
\text { - Reduction of initial lymphatic vessel density } \\
\text { - Increased leakage from lymphatic vessels } \\
\text { - Increased perilymphatic inflammation }\end{array}$ & $\begin{array}{l}\text { Weitman et al., 2013; Blum } \\
\text { et al., 2014; Savetsky et al., } \\
\text { 2014, 2015a; García Nores } \\
\text { et al., 2016; Hespe et al., } \\
\text { 2016; Nitti et al., } 2016\end{array}$ \\
\hline $\begin{array}{l}\text { Non-alcoholic } \\
\text { steatohepatitis } \\
\text { (NASH) }\end{array}$ & $\begin{array}{l}\text { Chronic liver disease and metabolic } \\
\text { syndrome characterized by hepatic } \\
\text { steatosis, inflammation, and fibrosis. } \\
\text { Can be induced by a combination of } \\
\text { high-fat diet and oxidized low-density } \\
\text { lipoprotein (oxLDL) administration in } \\
\text { mice }\end{array}$ & $\begin{array}{l}\text { - NASH-related cirrhosis can result in the development of } \\
\text { ascites } \\
\text { - Human NASH patients show increased lymphatic vessel } \\
\text { density in liver and induction of IL-13 pathway in hepatic } \\
\text { LECs } \\
\text { - Mice treated with oxLDL show increased hepatic LEC } \\
\text { IL-13 production } \\
\text { - oxLDL treatment of human LECs reduced PROX1 } \\
\text { expression in vitro. }\end{array}$ & $\begin{array}{l}\text { Yimin et al., 2012; Chung } \\
\text { and Iwakiri, 2013; } \\
\text { Tamburini et al., } 2019\end{array}$ \\
\hline
\end{tabular}

et al., 2016). This hypothesis is supported by previous studies demonstrating that inflammatory cytokine signaling enhanced LEC monolayer permeability in vitro (Cromer et al., 2014) and increased NO production elevated lymphatic permeability of collecting vessels in vivo (Scallan et al., 2015). Furthermore, it was demonstrated that perilymphatic inflammatory cell accumulation may contribute to lymphatic dysfunction and the pathogenesis of obesity via loss of LEC identity as gene expression of VEGFR-3, Prox1, and CCL21 was reduced in LECs isolated from sedentary, obese mice compared to lean controls (Hespe et al., 2016). Of note, impaired lymphatic function and leakiness in a subset of $\operatorname{Prox} 1^{+/-}$pups results in the effusion of lipid-rich chyle into the abdominal cavity from the mesentery lymphatics and evidence has shown that free fatty acids enriched in lymph promote adipogenesis in vitro, thus offering a possible mechanism relating lymphatic dysfunction and adipose tissue accumulation (Escobedo and Oliver, 2017). Support of the existence of cross-talk between the lymphatic system and adipose tissue also comes from recent studies demonstrating that weight loss in mice and reduction of adipose tissue in postmastectomy patients is able to improve lymphatic function and reduce tissue volume accumulation associated with lymphedema (Brorson, 2016; Nitti et al., 2016). Weight loss in a diet-induced obesity mouse model was shown to reverse both perilymphatic inflammation and iNOS expression and improvements were observed in lymphatic vessel density, lymphatic barrier integrity, and collecting vessel contractility (Nitti et al., 2016). Reduction of adipose tissue by longitudinal liposuction treatment with respect to limb was also shown to improve lymphatic function and the reduction of tissue fluid accumulation in patients diagnosed with postmastectomy arm lymphedema (Brorson, 2016) as well as patients diagnosed with primary lymphedema (Schaverien et al., 2018). Together, this data emphasizes the critical role the lymphatic vascular system has as a mediator in the pathogenesis of obesity. As obesity initially contributes to the development of a chronic inflammatory environment, this in turn results in impairment of lymphatic function which can then exacerbate the pathological consequences of obesity and present a significant risk to patients with elevated BMI and the development of lymphedema.

\section{IMPAIRED TRANSCRIPTION FACTOR SIGNALING RELATED TO LYMPHATIC DYSFUNCTION, OBESITY, AND DIABETES}

The PROX1 transcription factor is critical for LEC fate and differentiation during lymphatic development as well as the formation of the lymphatic vasculature during lymphangiogenesis and maturation into adulthood (Wigle and Oliver, 1999; Wigle et al., 2002; Ma and Oliver, 2017). Prox 1 null mutant mice die between embryonic (E) stage 14.5 and E15.0, and are characterized by severe edema due to the complete absence of the superficial lymphatic vascular network while normal development of the blood vasculature occurs (Wigle and Oliver, 1999). In contrast, Prox $1^{+/-}$pups also display edema at E14.5 yet maintain formation of a superficial lymphatic vascular plexus. However, many individuals die shortly after birth as a result of severe lymphatic dysfunction and accumulation of chyle in the peritoneal and thoracic cavities (Wigle and Oliver, 1999; Harvey et al., 2005). Surprisingly, a small proportion of Prox $1^{+/-}$mice generated on the NMRI genetic background are capable of surviving to adulthood (Wigle et al., 1999; Harvey et al., 2005), but develop adult-onset obesity with weight gain noticeable at nine weeks of age (Harvey et al., 2005). These Prox $1^{+/-}$individuals are characterized by both lymphatic mispatterning in the intestine and mesentery and impaired lymphatic transport as ingested fluorescent lipid leaked from the mesenteric lymphatic collecting vessels, indicative of perturbed vessel integrity and barrier function (Harvey et al., 2005; Escobedo et al., 2016). Therefore, this evidence provides a direct link of lymphatic dysfunction to the development and pathogenesis of obesity. Mechanistically, chyle containing lipid-rich lymph from Prox $1^{+/-}$mice promoted differentiation of 3T3-L1 preadipocytes into adipocytes. 
Differentiation was synergistically enhanced by the addition of insulin at a concentration of $10 \mu \mathrm{g} / \mathrm{mL}$ to chyle suggesting the presence of a factor in chyle that cooperates with insulin to promote differentiation. Thus, it was proposed that disruption of lymphatic vascular integrity promotes the ectopic growth of fat in lymphatic-rich regions due to stimulation of preadipocyte differentiation in addition to increased lipid storage in adipocytes (Harvey et al., 2005). Importantly, the development of obesity was directly linked to LEC maintenance of Prox1 expression in this model as conditional, endothelial cell-Proxi ${ }^{+/-}$mice similarly were characterized by impaired lymphatic vascular function and the development of obesity (Harvey et al., 2005). Furthermore, restoration of Prox 1 expression specifically within the lymphatic vasculature was capable of rescuing the obese phenotype in Prox1 ${ }^{+/-}$mice (Escobedo et al., 2016).

Several studies in humans have now linked PROX1 expression to the development of hyperlipidemia, obesity, and T2D (Horra et al., 2009; Kim et al., 2013; Kretowski et al., 2015; AdamskaPatruno et al., 2019). Familial combined hyperlipidemia (FCHL) is a complex genetic dyslipidemia characterized by elevated apolipoprotein $\mathrm{B}$, small, dense LDL particles, triglycerides, and total cholesterol (Ayyobi and Brunzell, 2003). Assessment of PROX1 expression, as well as the critical lymphatic transcription factor FOXC2 (Norrmen et al., 2009; Sabine et al., 2012, 2015; Fatima et al., 2016), in subcutaneous adipose tissue of a subset of FCHL patients and healthy control individuals identified a reduction of PROX1, FOXC2, or expression of both in the subset of FCHL subjects compared to controls, suggesting that lymphatic dysfunction may contribute to the FCHL phenotype (Horra et al., 2009). Furthermore, a genome-wide association study was performed in families from a Mongolian population that identified the single nucleotide polymorphism (SNP) rs1704198 on chromosome 1q32 associated with larger waist circumference that is located $251 \mathrm{~kb}$ away from the PROX1 gene. Additionally, this SNP was also associated with waist circumference in a replicate study using samples from Korean families and the 1q32 locus was previously reported in a linkage study using an American-Indian diabetes sample (Franceschini et al., 2008; Kim et al., 2013). Recent evidence has identified another SNP in the $5^{\prime}$ UTR of PROX1 (rs340874) that is a genetic risk factor for T2D (Dupuis et al., 2010; Lecompte et al., 2013; Kretowski et al., 2015; Hamet et al., 2017; Adamska-Patruno et al., 2019). Previous analysis of allelic variants (high-risk CC-genotype carriers and low risk allele $\mathrm{T}$ carriers) of the rs340874 SNP demonstrated that carriers of the PROX1 CC genotype presented elevated free fatty acid levels after high-fat meal intake and lower glucose utilization after high-carbohydrate meal intake in comparison to subjections with other PROX1 genotypes. Likewise, carriers of the PROX1 CC genotype were found to have higher visceral fat accumulation despite reduced daily food consumption (Kretowski et al., 2015). Moreover, analysis of non-diabetic PROX1 CC genotype carriers postprandially after challenges with high-carbohydrate (89\%) and normo-carbohydrate (45\%) meal intake showed altered metabolite profiles compared to low-risk allelic variant carriers including differences in glycerophosphocholine, glycerophosphoethanolamine, sphingolipid, leukotriene, fatty acid, oxidized fatty acid, amino acid, carnitine, bile acids, and amide levels, which may be associated with insulin resistance and T2D development (Adamska-Patruno et al., 2019).

The forkhead-box transcription factor FOXC2 is critical for regulation of lymphangiogenesis during embryonic development (Fatima et al., 2016) and for the formation and maturation of lymphatic valves and collecting vessels postnatally (Norrmen et al., 2009; Sabine et al., 2012, 2015). While inactivating mutations in FOXC2 are predominately associated with the development of a form of hereditary lymphedema, lymphedemadistichiasis syndrome (Fang et al., 2000; Dagenais et al., 2004), previous studies have also linked genetic variation in FOXC2 to obesity and diabetes and identified FOXC2 function as protective against obesity and insulin resistance (Cederberg et al., 2001; Kovacs et al., 2003; Carlsson et al., 2005). In mice, Foxc2 is found expressed in both white and brown adipose tissue and transgenic mice with increased expression of Foxc2 in adipose tissue were characterized by reduced cell size in intrabdominal white adipose tissue (Cederberg et al., 2001). Moreover, serum triglyceride, free fatty acids, plasma insulin and glucose content, weight, and lipid content were reduced in Foxc2 transgenic mice compared to control mice on a high fat diet. Of note, Foxc2 mRNA levels were also increased in epididymal white adipose tissue of WT mice fed a high-fat diet compared to individuals fed a standard diet, suggesting that FOXC2 acts as a metabolic regulator in protection against diet-induced obesity and insulin resistance (Cederberg et al., 2001). Clinically, a SNP in the putative FOXC2 promoter region, a C-512T transition, was identified in a population of Pima Indians which was associated with BMI and percentage of body fat in both male and female subjects as individuals homozygous for the C-512T allele had lower BMI than homozygous $\mathrm{C} / \mathrm{C}$ or heterozygous $\mathrm{C} / \mathrm{T}$ individuals. Additionally, the C-512T variant appeared to be involved in female subjects' regulation of basal glucose turnover and plasma triglyceride levels (Kovacs et al., 2003). Furthermore, an additional study from a Finnish population of T2D patients and control subjects did not identify a significant difference in the $\mathrm{C}-512 \mathrm{~T}$ allele and genotype distribution between the study subjects, but the $\mathrm{C} / \mathrm{C}$ genotype was associated with elevated BMI in T2D (Carlsson et al., 2005). From the patient studies above, it is not known whether the identified mutations are associated with lymphatic dysfunction and in actuality may primarily be related to alterations in hepatocyte function or adipogenic potential. However, the growing evidence supporting the relationship of metabolic syndrome and lymphatic dysfunction warrants further investigation of lymphatic function associated with these described patient mutations. Additionally, individuals suffering from hereditary lymphedema associated with mutations in transcription factors such as FOXC2 contributing to the development of lymphedema-distichiasis, or GATA2 contributing to the development Emberger syndrome (Mansour et al., 2010; Ostergaard et al., 2011), may be at risk for abnormal adipose deposition and development of obesity due to proliferation and hypertrophy of adipocytes in lymphedematous tissues (Zampell et al., 2012a; Mehrara and Greene, 2014). Nonetheless, 
continued studies of these patient populations are required for risk assessment.

\section{THE VEGF-C/VEGF-D/VEGFR-3 SIGNALING AXIS AND LYMPHATIC DYSFUNCTION IN THE PATHOGENESIS OF OBESITY AND DIABETES}

Vascular endothelial growth factors signaling through their respective VEGF receptor (VEGFR) tyrosine kinases provide a critical driving force for the growth of new vessels during angiogenesis and lymphangiogenesis (Karaman et al., 2018). In the lymphatic vasculature, VEGF-C-induced activation of VEGFR-3 predominately stimulates lymphangiogenesis (Karkkainen et al., 2004). In contrast, VEGF-D, which is capable of activation of both VEGFR-2 and VEGFR-3 in humans (Achen et al., 1998) but only VEGFR-3 in mice (Baldwin et al., 2001), was found to be dispensable for developmental lymphangiogenesis in mice (Baldwin et al., 2005) but its deficiency led to smaller, dysfunctional initial lymphatic vessels in the skin of adult mice (Paquet-Fifield et al., 2013). Independent of its function in the vasculature however, it was recently shown that VEGF-D deficiency significantly elevated cholesterol and triglyceride levels in an atherogenic mouse model via reduction of hepatic expression of syndecan 1, a receptor for chylomicron remnant uptake (Tirronen et al., 2018). In two studies of obese subjects, serum concentrations of VEGF-C were significantly elevated in overweight and obese individuals in addition to VEGF-A (Silha et al., 2005; Gomez-Ambrosi et al., 2010), but elevated VEGF-D was only detected in one report in women after gender segregation (Silha et al., 2005) whereas it was found to be reduced in obese individuals in a separate study using a similar population (Gomez-Ambrosi et al., 2010). It has also been shown in human patients that plasma VEGF-A levels were more strongly correlated with BMI and waist circumference than serum VEGF-C, but VEGF-C levels were more strongly correlated with dyslipidemia (Wada et al., 2011). Importantly, the growth of visceral fat and expansion of white adipose tissue associated with obesity results in a hypoxic environment that activates increased levels of HIF1- $\alpha$ which in turn increases VEGF-A to stimulate angiogenesis and support rapid growth of adipose tissue, but also leads to an upregulation of inflammatory adipokines and promotes tissue fibrosis leading to adipose tissue dysfunction (Rutkowski et al., 2009). Moreover, blocking angiogenesis in young individuals of the obese, leptin deficient $o b / o b$ mouse strain via treatment with several inhibitors acting on the endothelium, including TNP-470, angiostatin, and endostatin, prevented expansion of adipose tissue and returned mice to normative metabolic function in adulthood (Rupnick et al., 2002).

More recently, evidence has shown that lymphatic dysfunction associated with inactivation of VEGFR-3, which is classically associated with lymphedema in Milroy's disease (Butler et al., 2007), is linked to the pathogenesis of obesity and adipose tissue accumulation (Rutkowski et al., 2010) and that targeting this signaling pathway to improve lymphatic function may provide resolution of metabolic syndrome. Two separate mouse models of impaired VEGFR-3 signaling, the Chy (Karkkainen et al., 2001) and K14-VEGFR-3-Ig (Makinen et al., 2001), are both characterized by lack of dermal lymphatic capillaries and presence of lymphedema, but the skin of Chy mice consisted of higher deposition of collagen and fat (Rutkowski et al., 2010). The increase in collagen and lipid content in the tail dermis of Chy mice was attributed to remodeling of collagen and fat density to decrease dermal elasticity and normalize tissue hydraulic conductivity to make tissue easier to swell within the context of edema. Alternatively, fluid accumulation in the K14-VEGFR-3-Ig mice, which expresses a soluble VEGFR3 -Ig construct in the skin under the keratin 14 promoter to trap VEGF-C/D, led to increased hydraulic conductivity to compensate for changes in interstitial fluid pressure, thus highlighting important pathological and functional differences although the lymphedema phenotype is similar in both strains (Rutkowski et al., 2010).

In addition to its role in the lymphatic vasculature, VEGFR-3 is also expressed by a subset of macrophages and VEGF-C and VEGF-D are able to induce their chemotactic migration (Skobe et al., 2001a,b; Schoppmann et al., 2002; Stepanova et al., 2007; Zhang et al., 2014). A more recent study utilized K14VEGFR-3-Ig mice to investigate the effects of VEGFR-3 signaling inhibition on adipose tissue growth and insulin sensitivity in mice fed a high-fat diet. VEGFR-3 signaling inhibition improved systemic insulin sensitivity and protected against high-fat diet induced fatty liver disease as adipocyte size and adipose tissue inflammation were reduced in K14-VEGFR-3-Ig mice compared to controls (Karaman et al., 2015). In contrast, infiltration of pro-inflammatory M1 macrophages, which express higher levels of Vegfr3, was stimulated in control mice fed high-fat diet, which was attributed to elevated adipocyte expression of VEGF-C and VEGF-D. However, blockage of VEGF-C and VEGF-D in K14-VEGFR-3-Ig mice on high-fat diet, or by utilization of a VEGFR-3 blocking antibody in leptin deficient $d b / d b$ mice, protected against the development of insulin resistance and infiltration of pro-inflammatory macrophages. Thus, inhibition of VEGFR-3 signaling suppressed a shift to increased M1/M2 macrophage ratio associated with obesity (Lumeng et al., 2007; Karaman et al., 2015). Furthermore, by utilizing K14-VEGF$\mathrm{C}$ mice that overexpress human VEGF-C in the skin it was shown that these mice more rapidly gained weight, became insulin resistant, had increased ectopic lipid accumulation in adulthood compared to WT littermates on normal chow, and pro-inflammatory macrophage infiltration into adipose tissue was significantly increased (Karaman et al., 2016). Conversely, by stimulating adipose-specific lymphangiogenesis via VEGFR-3 to resolve metabolic syndrome in high-fat diet fed mice, Chakraborty et al. (2019) recently demonstrated that adipose-specific VEGF-D overexpression induced de novo lymphangiogenesis and these transgenic mice exhibited improved metabolic responsiveness and reduced obesityassociated macrophage accumulation as immune trafficking was increased from adipose tissue. Furthermore, stimulation of the VEGF-C/VEGF-D/VEGFR-3 signaling axis was shown 
to improve clearance of contact hypersensitivity-induced inflammation in obese mice as injections of recombinant VEGF-C improved lymphatic function (Savetsky et al., 2015a). Additionally, treatment of atherosclerotic prone, high-fat diet fed $\mathrm{Ldlr}^{-/}$mice with VEGF-C $152 \mathrm{~S}$ resulted in improved lymphatic molecular transport and reduction of both plaque formation and macrophage accumulation, which was associated predominately with improved lymphatic contraction frequency (Milasan et al., 2019).

Complications from defects in the lymphatic vasculature in diabetic individuals are associated with perturbed wound healing, which can manifest in secondary lymphedema arising from disruption of the lymphatics (Rutkowski et al., 2006; Lin et al., 2013). However, improving VEGFR-3 availability at the cell surface of LECs by inhibition of epsin-mediated degradation was recently shown to improve lymphangiogenesis in diabetic mice, which improved resolution of wound healing and secondary lymphedema in a tail edema model ( $\mathrm{Wu}$ et al., 2018). Epsins 1 and 2 are ubiquitin-binding adaptor proteins involved in endocytosis and regulate VEGFR-3 bioavailability at the surface of LECs during lymphatic collecting vessel maturation and valve formation (Liu et al., 2014). In the context of adult diabetic mice generated by treatment with streptozotocin and fed a high-fat diet, hyperglycemia-induced oxidative stress increased epsin expression, mediated by phosphorylation of c-Src and the transcription factor AP-1, which promoted degradation of newly synthesized VEGFR-3. Inducible, LECspecific deletion of epsins was then able to attenuate VEGFR-3 degradation and thus maintained VEGFR-3 bioavailability at the LEC cell surface to improve lymphangiogenesis and restore lymphatic function (Wu et al., 2018). Collectively, these results demonstrate a critical role for the VEGF-C/VEGF-D/VEGFR3 signaling axis in lymphatic dysfunction associated with the pathogenesis of obesity and metabolic syndrome. Yet from the studies discussed, it is clear that there are underlying contextual factors contributing to the differences observed in Chy and K14-VEGFR-3-Ig models as well as differences in tissue-specific activation of VEGFR-3 signaling. Although both the Chy and K14-VEGFR-3-Ig models are characterized by the lack of dermal lymphatics, the differences in tissue remodeling exhibited by both models in response to changes in interstitial pressure may be attributable to the background strains used, $\mathrm{CH} 3$ for Chy mice and C57BL/6 for K14-VEGFR-3-Ig mice, or individual genetic manipulation (Rutkowski et al., 2010). Variations between different mouse strains in immune cell activity, inflammation, vascular remodeling and response, and wound healing have previously been characterized (Bendall et al., 2002; Ryan et al., 2002; Rajnoch et al., 2003; Chan et al., 2005; Marques et al., 2011) as well as the lymphangiogenic response in the mouse cornea micropocket assay and sutureinduced corneal neovascularization model (Regenfuss et al., 2010). Furthermore, the differences observed between activation of VEGFR-3 signaling in several of these models is attributable to the physiological responses induced. It was noted that adiposespecific overexpression of VEGF-D resulted in adipose tissue fibrosis, macrophage accumulation, and elevated cytokine levels similar to what was observed in mice with overexpression of
VEGF-C under the keratin 14 promoter. However, de novo lymphangiogenesis was observed in mice with adipose-specific overexpression of VEGF-D but not mice with overexpressed VEGF-C in the skin (Karaman et al., 2016; Lammoglia et al., 2016; Chakraborty et al., 2019). Therefore, it has been proposed that localization of the initiation of the lymphangiogenic gradient from the adipose tissue, and not the skin, has a role in supporting new lymphatic growth and the resolution of inflammatory cell accumulation in the context of obesity (Chakraborty et al., 2019). Thus, the localization of VEGFR3 signaling has a critical role in determining physiological responses in the context of obesity and chronic inflammation and the role of adipose-specific VEGFR-3 expression needs to be further elucidated.

While stimulation of lymphangiogenesis is an attractive therapeutic target in obesity and metabolic syndrome to resolve insulin resistance, ectopic lipid deposition, and local immune cell accumulation, careful consideration is needed for the use of therapies stimulating the VEGF-C/VEGFD/VEGFR-3 signaling axis. Notably, lymphatic vessels become largely independent of VEGF-C/VEGFR-3 signaling after early postnatal development (Karpanen et al., 2006) with the exception of intestinal lacteals, which have been shown to be dependent on VEGF-C/VEGFR-3 signaling for maintenance in adult mice (Nurmi et al., 2015). Furthermore, the effects of tissue-specific activation of VEGFR-3 signaling need to be taken into consideration. As noted previously, there are differences in the lymphangiogenic response between skinspecific and adipose-specific activation of VEGFR-3 (Karaman et al., 2016; Lammoglia et al., 2016; Chakraborty et al., 2019). Additionally, the roles of VEGFR-3 signaling activation beyond the vasculature, such as in regulation of chylomicron remnant removal by hepatocytes and lipoprotein metabolism (Tirronen et al., 2018), need to be carefully considered in the development of therapeutic strategies. Although the development of targeted therapeutics for tissue specific activation of VEGFR-3 is currently a limitation, increasing evidence has shown that targeting this pathway to improve lymphatic function within this pathological context warrants further investigation. Thus, strategies to specifically stimulate adiposespecific lymphangiogenesis may be viable options for therapy to improve inflammatory cell clearance, similar to strategies targeting lymphatic expansion in an inflammatory site-specific manner within the context of a model of chronic skin inflammation (Schwager et al., 2018).

\section{ABNORMAL NO SIGNALING AND IMPAIRED LYMPHATIC FUNCTION IN OBESITY AND METABOLIC SYNDROME}

Contributing to its pathogenesis, numerous studies utilizing both genetic and non-genetic, diet-induced obesity and metabolic syndrome mouse models (Table 1) have demonstrated that lymph and cholesterol transport, as well as migration of antigenpresenting dendritic cells, is impaired in obese mice compared to lean controls (Lim et al., 2009, 2013; Chakraborty et al., 
2010; Dixon, 2010; Martel et al., 2013; Weitman et al., 2013). Underlying this impaired ability of the lymphatic vasculature to support functional transport, several studies have now implicated the role of iNOS and perturbed NO signaling as a mechanism related to poor lymphatic contraction observed in obesity, diabetes, and other models of metabolic syndrome (Zawieja et al., 2012; Blum et al., 2014; Scallan et al., 2015; Hespe et al., 2016; Torrisi et al., 2016). NO is a gaseous free radical that is known to have strong regulatory effects on vasodilation and permeability in the blood vasculature (Kubes and Granger, 1992; Yuan, 2006; Duran et al., 2010) and it is produced by three isoforms of NO synthase, including neuronal NOS (nNOS, NOS I), inducible NOS (iNOS, NOS II), and endothelial NOS (eNOS, NOS III) (Förstermann and Sessa, 2012). In the lymphatic endothelium, eNOS expression, and thus NO production, is regulated by both intracellular calcium levels and vessel shear stress (Leak et al., 1995; Gashev et al., 2002; Tsunemoto et al., 2003). Here, NO signaling serves dual roles as NO produced by LECs, and in particular from the valve/sinus region (Bohlen et al., 2011), functions to control relaxation after a contraction (diastole) in lymphatic collecting vessels (Gashev et al., 2002; Tsunemoto et al., 2003; Gasheva et al., 2006) and exogenous sources of NO have been shown to slow lymphatic contraction frequency (von der Weid et al., 2001; Liao et al., 2011; Zawieja et al., 2016). Thus, NO signaling serves a key role in regulating lymph transport and lymphatic vessel function in a controlled, responsive manner to various stimuli.

As described above, perilymphatic iNOS expression is increased in obese mice associated with an increased inflammatory response (Savetsky et al., 2015a; Hespe et al., 2016; Nitti et al., 2016) and it has been previously shown that under an acute inflammatory response in the mouse, iNOSexpressing inflammatory cells attenuate lymphatic contraction via increased NO production (Liao et al., 2011). Supporting the role of iNOS signaling in the development of impaired lymphatic function and the pathogenesis of obesity, utilization of the selective iNOS inhibitor $1400 \mathrm{~W}$ was able to improve lymphatic contractile function in obese mice (Torrisi et al., 2016). Moreover, diet-induced weight loss in obese mice also decreased perilymphatic inflammation and iNOS expression, which was also associated with decreased lymphatic leakiness and improved lymphatic contractile function (Nitti et al., 2016). Work from Scallan et al. (2015) has however identified a paradoxical role for NO signaling in the lymphatics in the context of either healthy collecting vessels or those from the $d b / d b$ mouse model of T2D. Here, increased NO production was shown to increase lymphatic permeability in collecting vessels of healthy mice, but restoration of NO signaling in leptin receptor-deficient $d b / d b$ mice was shown to reduce permeability and rescue lymphatic barrier dysfunction. To activate signaling mechanisms functioning downstream of NO signaling in $d b / d b$ mice, the authors demonstrated that pharmacological inhibition of phosphodiesterase 3 (PDE3) was able to rescue lymphatic barrier dysfunction by suppressing PDE3 mediated degradation of cyclic AMP, which activates $\mathrm{PKA} / \mathrm{Epac1}$ to maintain endothelial barrier function. It was then proposed that low levels of cGMP from reduced NO bioavailability in diabetic mice relieves the inhibition of PDE3 and in turn, high insulin or leptin levels, as occur in T2D, promote phosphorylation and activation of PDE3 which results in loss of cAMP and impaired signaling through PKA/Epac1 (Scallan et al., 2015). In support of reduced NO bioavailability contributing to an impaired lymphatic function in the context of metabolic syndrome, it was also shown that the thoracic ducts of Sprague-Dawley rats under a high-fructose-fed diet, a model of metabolic syndrome, were characterized by a reduction in eNOS expression coupled to impaired flow responses (Zawieja et al., 2016). In vitro, acute insulin signaling activated eNOS phosphorylation mediated by PI3K/Akt signaling in LECs, but prolonged hyperinsulinemia and hyperglycemia promoted insulin resistance, impaired PI3K/Akt/eNOS signaling, mitochondrial function, and NO bioavailability, and also increased lymphatic permeability. The increased lymphatic permeability promoted by hyperglycemia and hyperinsulinemia was then associated with a significant increase in NF- $\kappa$ B nuclear translocation (Lee et al., 2018). While the role of NO signaling within the context of obesity and metabolic syndrome remains incompletely understood, the current data demonstrates that both lymphatic barrier function and contractility are susceptible to elevated levels of NO production, while barrier function is also susceptible to markedly impaired NO production. Evidence from the current studies then suggests that reduction of exogenous $\mathrm{NO}$ donors and preservation of endogenous NO synthase function within the lymphatic endothelium may prove as a promising therapeutic strategy.

\section{IMPROVING LYMPHATIC FUNCTION FOR THERAPEUTIC TREATMENT OF METABOLIC SYNDROME}

Provided the growing evidence that the relationship between lymphatic dysfunction and the pathogenesis of metabolic syndrome, and obesity in particular, is bi-directional and reciprocating (Mehrara and Greene, 2014; Escobedo and Oliver, 2017), methods to improve lymphatic function have become attractive for therapeutics, including previously proposed VEGF$\mathrm{C}$ related therapies. Several recent studies have proposed other various methods to improve lymphatic function, including both the use of pharmacological agents as well as behavioral and lifestyle changes (Table 2).

In a model of diet-induced obesity, Torrisi et al. (2016) demonstrated that treatment with topical tacrolimus, an inhibitor of $\mathrm{T}$ cell differentiation, improved lymphatic vessel density and lymphatic pumping frequency, reduced perilymphatic accumulation of leukocytes, macrophages, $\mathrm{T}$ cells, and perilymphatic iNOS expression in the hindlimbs of mice, whereas direct inhibition of iNOS with the small molecule inhibitor $1400 \mathrm{~W}$ did not improve lymphatic function. Importantly, adipose tissue volume was not significantly changed at the site of tacrolimus application, suggesting that increased lymphatic density resulted from capillary LEC proliferation 
TABLE 2 | Therapeutics targeting lymphatic function improvement for treatment of obesity, diabetes, and metabolic syndrome.

\begin{tabular}{|c|c|c|c|}
\hline Therapeutic & Target & Effect on lymphatic function & References \\
\hline Tacrolimus & $\begin{array}{l}\text { Macrolide calcineurin inhibitor that } \\
\text { suppresses T cell } \\
\text { proliferation/differentiation }\end{array}$ & $\begin{array}{l}\text {-Reduces perilymphatic inflammation in skin tissue of } \\
\text { obese mice } \\
\text { •Improves lymphatic transport capacity from distal injection } \\
\text { site to the popliteal lymph node } \\
\text {-Improves dendritic cell migration capacity and lymphatic } \\
\text { contractile function }\end{array}$ & Torrisi et al., 2016 \\
\hline Cilostamide & Phosphodiesterase 3 (PDE3) inhibitor & $\begin{array}{l}\text {-Reduces lymphatic permeability and leakage in collecting } \\
\text { vessels of } d b / d b \text { mice }\end{array}$ & Scallan et al., 2015 \\
\hline Y-27632 & $\begin{array}{l}\text { Rho-associated protein kinase (ROCK) } \\
\text { inhibitor }\end{array}$ & $\begin{array}{l}\text {-Induces intestinal lacteal junction "zippering" and } \\
\text { conversion of "button-like" cell-cell junctions to linear } \\
\text { junctions } \\
\text { •Reduces chylomicron uptake into lacteals and transport to } \\
\text { mesenteric lymphatics }\end{array}$ & Zhang et al., 2018 \\
\hline Exercise & $\begin{array}{l}\text { Behavioral/lifestyle change with } \\
\text { improvements in mediating chronic } \\
\text { inflammation, glucose intolerance and } \\
\text { endothelial dysfunction in obesity }\end{array}$ & $\begin{array}{l}\text {-Improves lymphatic contractile function } \\
\text { - Reduces perilymphatic immune cell accumulation in skin } \\
\text { tissue } \\
\text {-Reduces expression of inflammatory, } \\
\text { anti-lymphangiogenic cytokines including TNF- } \alpha \text {, IFN- } \gamma \text {, } \\
\text { and IL-1 } \beta \text { in skin tissue } \\
\text { - Reduces lymphatic leakiness and improves dendritic cell } \\
\text { migration capacity } \\
\text {-Improves expression of LEC gene expression of Vegfr3, } \\
\text { Prox1, and Ccl } 21\end{array}$ & Hespe et al., 2016 \\
\hline Ketogenic diet & $\begin{array}{l}\text { Behavioral/lifestyle change associated } \\
\text { with incorporation of high-fat, } \\
\text { low-carbohydrate diet to improve } \\
\text { weight loss }\end{array}$ & $\begin{array}{l}\text {-Increases circulating levels of } \beta \text {-hydroxybutyrate ketone } \\
\text { body in vivo, which promotes LEC proliferation, migration, } \\
\text { and sprouting in vitro } \\
\text { - Stimulated corneal lymphatic growth after injury } \\
\text {-Improved resolution of lymphedema in model of tail } \\
\text { microsurgical excision of lymphatic vessels }\end{array}$ & $\begin{array}{l}\text { Keith et al., 2017; } \\
\text { García-Caballero et al., } \\
2019\end{array}$ \\
\hline
\end{tabular}

with inhibition of obesity-mediated chronic inflammation (Torrisi et al., 2016). In support of targeting perilymphatic inflammation to improve lymphatic function in the context of obesity, it was also shown that behavioral changes to introduce aerobic exercise training, independent of weight loss, were effective in decreasing perilymphatic inflammatory cell accumulation and improving lymphatic function (Hespe et al., 2016). Additional evidence adapting behavioral and lifestyle changes has suggested that long-term incorporation of a high-fat, low-carbohydrate ketogenic diet improves weight loss and limb volume reduction in patients with lymphedema and obesity (Keith et al., 2017). Evidence in mice has demonstrated that LECs rely on fatty acid $\beta$-oxidation (FAO) for proliferation, migration, and sprouting, and generation of acetyl-coenzyme A (acetyl-CoA) by FAO facilitates LEC differentiation via acetylation of histone at lymphangiogenic genes, which promotes their expression (Wong et al., 2016). Prolonged incorporation of a high-fat, low-carbohydrate ketogenic diet results in the elevated production of ketone bodies secreted from the liver, which are then able to be oxidized in mitochondria into two molecules of acetyl-CoA in extrahepatic tissues (Puchalska and Crawford, 2017). To characterize the role of ketone body oxidation in the lymphatic vasculature, García-Caballero et al. (2019) recently demonstrated that elevation of lymph ketone bodies in mice, by either a ketogenic diet or administration of the ketone body $\beta$-hydroxybutyrate, stimulated lymphangiogenesis after corneal injury and myocardial infarction. Studies investigating high-fat diet induced obesity typically utilize a high-fat diet chow consisting of $60 \% \mathrm{kcal}$ obtained from fat, $20 \%$ from protein, and $20 \%$ from carbohydrates resulting in accelerated weight gain and progression to obesity (Weitman et al., 2013; Savetsky et al., 2014; García Nores et al., 2016; Hespe et al., 2016; Nitti et al., 2016; Torrisi et al., 2016). In contrast, high-fat, lowcarbohydrate diet (ketogenic) chow generally consists of $>70 \%$ of kcal obtained from fats, $<5 \%$ obtained from carbohydrates, and the remaining $\sim 25 \%$ obtained from proteins to induce a ketogenic state and the higher production of ketone bodies as a result of activated FAO (Kennedy et al., 2007; Nilsson et al., 2016; Puchalska and Crawford, 2017). Supporting a stimulated lymphangiogenesis response, ketone body oxidation was shown to increase acetyl-CoA generation, which was incorporated into the TCA cycle to support LEC nucleotide synthesis. Additionally, reducing equivalents generated from oxidation were incorporated for mitochondrial respiration and ATP production. Moreover, it was also shown in a mouse model of secondary lymphedema, via microsurgical ablation of lymphatic vessels in the tail, that a ketogenic diet improved lymphatic function and growth, reduced accumulation of anti-inflammatory $\mathrm{CD}^{+}$and $\mathrm{CD}^{+}{ }^{+} \mathrm{T}$ cells, and reduced edema (García-Caballero et al., 2019).

In addition to therapeutically targeting the inflammatory environment to improve lymphatic function, several studies have proposed methods of modifying lymphatic barrier function within the context of obesity and diabetes to improve outcome. 
As described previously, metabolic syndrome and insulin resistance is associated with impaired NO synthase expression in LECs, resulting in leaky lymphatic collecting vessels and impaired contractile activity. However, Scallan et al. (2015) demonstrated that lymphatic barrier function could be improved in a mouse model of T2D by inhibiting PDE3 with the pharmacological inhibitor cilostamide, thereby providing a method to improve interstitial fluid clearance during inflammation. Additionally, it was also recently proposed that induction of intestinal lacteal junction "zippering" could protect against diet-induced obesity (Zhang et al., 2018). Zhang et al. (2018) recently demonstrated that inducible, pan-endothelial-specific deletion of the VEGF-A receptors VEGFR-1/FLT1 and neuropilin 1 (NRP1) protected mice from high-fat diet-induced obesity. Mice lacking endothelial Flt1 and Nrp1 were characterized by lacteals consisting of more linear, "zipper-like" junctions compared to control mice characterized by lacteals with discontinuous "button-like" junctions. This conversion from discontinuous to linear junctions in mutants then prevented absorption of chylomicrons from the intestine. Endothelial-specific deletion of both receptors increased the bioavailability of VEGF-A to activate pathways downstream of LEC VEGFR-2 signaling, which includes inhibition of LEC VE-cadherin cytoskeletal anchoring. Interestingly, short-term treatment of WT mice with the Rho-associated protein kinase (ROCK) inhibitor Y27632 disrupted cytoskeletal VE-cadherin anchoring in lacteals and induced the formation of linear junctions, mimicking the effect of endothelial-specific deletion of Flt1 and Nrp1, which also resulted in reduced chylomicron absorption (Zhang et al., 2018). Therefore, targeting cytoskeletal regulation of lymphatic junctions may prove promising for therapeutic development to suppress dietary lipid absorption in prevention of and resolution of obesity, but further studies assessing the effects such drugs that regulate cytoskeletal activity are warranted. Collectively, these studies demonstrate that pharmacological or behavioral therapeutics focused on improving lymphatic function may function to improve outcomes in obese and metabolic syndrome patients, including those who also have or are at risk for lymphedema. However, further studies are required to assess how combined therapies may be adapted and to specifically determine what molecular mechanisms underlie perilymphatic inflammatory cell accumulation and lymphatic dysfunction.

\section{REFERENCES}

Achen, M. G., Jeltsch, M., Kukk, E., Makinen, T., Vitali, A., Wilks, A. F., et al. (1998). Vascular endothelial growth factor D (VEGF-D) is a ligand for the tyrosine kinases VEGF receptor 2 (Flk1) and VEGF receptor 3 (Flt4). Proc. Natl. Acad. Sci. U.S.A. 95, 548-553.

Adamska-Patruno, E., Godzien, J., Ciborowski, M., Samczuk, P., Bauer, W., Siewko, K., et al. (2019). The type 2 diabetes susceptibility PROX1 gene variants are associated with postprandial plasma metabolites profile in non-diabetic men. Nutrients 11:E882.

Ayyobi, A. F., and Brunzell, J. D. (2003). Lipoprotein distribution in the metabolic syndrome, type 2 diabetes mellitus, and familial combined hyperlipidemia. Am. J. Cardiol. 92:4A. doi: 10.1016/s0002-9149(03)00613-1

Baldwin, M. E., Catimel, B., Nice, E. C., Roufail, S., Hall, N. E., Stenvers, K. L., et al. (2001). The specificity of receptor binding by vascular endothelial growth

\section{CONCLUDING REMARKS}

The growing obesity epidemic presents a worldwide health concern as excess weight gain is associated with elevated risk for development of several diseases, but most notably cardiovascular disease and diabetes (Engin, 2017). As the population of obese and metabolic syndrome individuals continues to grow, novel therapeutic developments are required to meet this need. The studies summarized in this review underscore the importance of the lymphatic vascular system in the pathogenesis of obesity, diabetes, and metabolic syndrome, yet our understanding of the molecular mechanisms and signaling pathways involved in the cross-talk between these diseases and the lymphatic system is wholly incomplete. The field of developmental lymphatic biology is continuing to grow as new mechanisms related to LEC differentiation, morphogenesis, maintenance and function continue to be identified, but additional comprehensive studies are required to understand the role of the lymphatic system in pathological states. Moreover, it is important to consider that the lymphatic vasculature interfaces and communicates with numerous tissues, including the blood vasculature, adipose tissue, and inflammatory cells associated with pathological obesity and metabolic syndromes. Therefore, studies investigating combined therapies to target multiple aspects of this pathological environment, such as inhibition of inflammatory cell accumulation, modulation of lymphatic barrier function, and behavioral changes, such as diet modifications and incorporation of exercise regimens, should be of future focus.

\section{AUTHOR CONTRIBUTIONS}

PN contributed to the writing and editing of the manuscript, and creation of tables. TK contributed to the concepts, editing, and final formatting of the manuscript.

\section{FUNDING}

This work was supported by the National Institutes of Health Grants R01HL126920 and R01HL144129 (to TK) and 5T32HL094293 (to PN).

factor-d is different in mouse and man. J. Biol. Chem. 276, 19166-19171. doi: 10.1074/jbc.M100097200

Baldwin, M. E., Halford, M. M., Roufail, S., Williams, R. A., Hibbs, M. L., Grail, D., et al. (2005). Vascular endothelial growth factor D is dispensable for development of the lymphatic system. Mol. Cell Biol. 25, 2441-2449.

Baluk, P., Fuxe, J., Hashizume, H., Romano, T., Lashnits, E., Butz, S., et al. (2007). Functionally specialized junctions between endothelial cells of lymphatic vessels. J. Exp. Med. 204, 2349-2362.

Bastard, J. P., Jardel, C., Bruckert, E., Blondy, P., Capeau, J., Laville, M., et al. (2000). Elevated levels of interleukin 6 are reduced in serum and subcutaneous adipose tissue of obese women after weight loss. J. Clin. Endocrinol. Metab. 85, 3338-3342. doi: 10.1210/jcem.85.9.6839

Belalcazar, L. M., Haffner, S. M., Lang, W., Hoogeveen, R. C., Rushing, J., Schwenke, D. C., et al. (2013). Lifestyle intervention and/or statins for the reduction of 
C-reactive protein in type 2 diabetes: from the look AHEAD study. Obesity (Silver Spring) 21, 944-950.

Bendall, J. K., Heymes, C., Wright, T. J., Wheatcroft, S., Grieve, D. J., Shah, A. M., et al. (2002). Strain-dependent variation in vascular responses to nitric oxide in the isolated murine heart. J. Mol. Cell Cardiol. 34, 1325-1333. doi: 10.1006/ jmcc.2002.2083

Bernier-Latmani, J., Sabine, A., and Petrova, T. V. (2015). Meet me in the middle: dual origins of dermal lymphatic vasculature in mammals. Circ. Res. 116, 1630-1632. doi: 10.1161/circresaha.115.306436

Bertram, C. D., Macaskill, C., Moore, J. E., and Jr. (2011). Simulation of a chain of collapsible contracting lymphangions with progressive valve closure. J. Biomech. Eng. 133:011008.

Blum, K. S., Karaman, S., Proulx, S. T., Ochsenbein, A. M., Luciani, P., Leroux, J. C., et al. (2014). Chronic high-fat diet impairs collecting lymphatic vessel function in mice. PLoS ONE 9:e94713. doi: 10.1371/journal.pone.0094713

Bohlen, H. G., Gasheva, O. Y., and Zawieja, D. C. (2011). Nitric oxide formation by lymphatic bulb and valves is a major regulatory component of lymphatic pumping. Am. J. Physiol. Heart Circ. Physiol. 301, H1897-H1906.

Brorson, H. (2016). Liposuction in lymphedema treatment. J. Reconstr. Microsurg. 32, 56-65. doi: 10.1055/s-0035-1549158

Bruun, J. M., Helge, J. W., Richelsen, B., and Stallknecht, B. (2006). Diet and exercise reduce low-grade inflammation and macrophage infiltration in adipose tissue but not in skeletal muscle in severely obese subjects. Am. J. Physiol. Endocrinol. Metab. 290, E961-E967. doi: 10.1152/ajpendo.00506.2005

Butler, M. G., Dagenais, S. L., Rockson, S. G., and Glover, T. W. (2007). A novel VEGFR3 mutation causes Milroy disease. Am. J. Med. Genet. A 143A, 1212-1217. doi: 10.1002/ajmg.a.31703

Carlsson, E., Groop, L., and Ridderstrale, M. (2005). Role of the FOXC2 -512C > T polymorphism in type 2 diabetes: possible association with the dysmetabolic syndrome. Int. J. Obes (Lond.) 29, 268-274. doi: 10.1038/sj.ijo.0802876

Cederberg, A., Gronning, L. M., Ahren, B., Tasken, K., Carlsson, P., and Enerback, S. (2001). FOXC2 is a winged helix gene that counteracts obesity, hypertriglyceridemia, and diet-induced insulin resistance. Cell 106, 563-573. doi: 10.1016/s0092-8674(01)00474-3

Chakraborty, A., Barajas, S., Lammoglia, G. M., Reyna, A. J., Morley, T. S., Johnson, J. A., et al. (2019). Vascular endothelial growth factor-D (VEGF-D) overexpression and lymphatic expansion in murine adipose tissue improves metabolism in obesity. Am. J. Pathol. 189, 924-939. doi: 10.1016/j.ajpath.2018. 12.008

Chakraborty, S., Zawieja, S., Wang, W., Zawieja, D. C., and Muthuchamy, M. (2010). Lymphatic system: a vital link between metabolic syndrome and inflammation. Ann. N. Y. Acad. Sci. 1207(Suppl. 1), E94-E102. doi: 10.1111/ j.1749-6632.2010.05752.x

Chan, C. K., Pham, L. N., Zhou, J., Spee, C., Ryan, S. J., and Hinton, D. R. (2005). Differential expression of pro- and antiangiogenic factors in mouse strain-dependent hypoxia-induced retinal neovascularization. Lab. Invest. 85, 721-733. doi: 10.1038/labinvest. 3700277

Chawla, A., Nguyen, K. D., and Goh, Y. P. (2011). Macrophagemediated inflammation in metabolic disease. Nat. Rev. Immunol. 11, 738-749.

Choi, I., Lee, S., and Hong, Y. K. (2012). The new era of the lymphatic system: no longer secondary to the blood vascular system. Cold Spring Harb. Perspect. Med. 2:a006445.

Chung, C., and Iwakiri, Y. (2013). The lymphatic vascular system in liver diseases: its role in ascites formation. Clin. Mol. Hepatol. 19, 99-104.

Cifarelli, V., and Eichmann, A. (2019). The intestinal lymphatic system: functions and metabolic implications. Cell Mol. Gastroenterol. Hepatol. 7, 503-513.

Clark, B., Sitzia, J., and Harlow, W. (2005). Incidence and risk of arm oedema following treatment for breast cancer: a three-year follow-up study. QJM 98, 343-348. doi: 10.1093/qjmed/hci053

Clavin, N. W., Avraham, T., Fernandez, J., Daluvoy, S. V., Soares, M. A., Chaudhry, A., et al. (2008). TGF-betal is a negative regulator of lymphatic regeneration during wound repair. Am. J. Physiol. Heart Circ. Physiol. 295, H2113-H2127. doi: 10.1152/ajpheart.00879.2008

Crescenzi, R., Donahue, P. M. C., Weakley, S., Garza, M., Donahue, M. J., and Herbst, K. L. (2019). Lipedema and dercum's disease: a new application of bioimpedance. Lymphat. Res. Biol. 17, 671-679.
Crescenzi, R., Marton, A., Donahue, P. M. C., Mahany, H. B., Lants, S. K., Wang, P., et al. (2018). Tissue sodium content is elevated in the skin and subcutaneous adipose tissue in women with lipedema. Obesity (Silver Spring) 26, 310-317.

Cromer, W. E., Zawieja, S. D., Tharakan, B., Childs, E. W., Newell, M. K., and Zawieja, D. C. (2014). The effects of inflammatory cytokines on lymphatic endothelial barrier function. Angiogenesis 17, 395-406.

Dagenais, S. L., Hartsough, R. L., Erickson, R. P., Witte, M. H., Butler, M. G., and Glover, T. W. (2004). Foxc2 is expressed in developing lymphatic vessels and other tissues associated with lymphedema-distichiasis syndrome. Gene Expr. Patterns 4, 611-619. doi: 10.1016/j.modgep.2004.07.004

Daugherty, A., Tall, A. R., Daemen, M., Falk, E., Fisher, E. A., Garcia-Cardena, G., et al. (2017). Recommendation on design, execution, and reporting of animal atherosclerosis studies: a scientific statement from the american heart association. Arterioscler. Thromb Vasc. Biol. 37:e131-157. doi: 10.1161/atv. 0000000000000062

De Pergola, G., and Silvestris, F. (2013). Obesity as a major risk factor for cancer. J. Obes. 2013, 291546.

Dixon, J. B. (2010). Lymphatic lipid transport: sewer or subway? Trends Endocrinol. Metab. 21, 480-487.

Dupuis, J., Langenberg, C., Prokopenko, I., Saxena, R., Soranzo, N., Jackson, A. U., et al. (2010). New genetic loci implicated in fasting glucose homeostasis and their impact on type 2 diabetes risk. Nat. Genet. 42, 105-116.

Duran, W. N., Breslin, J. W., and Sanchez, F. A. (2010). The NO cascade, eNOS location, and microvascular permeability. Cardiovasc. Res. 87, 254-261.

Engin, A. (2017). The definition and prevalence of obesity and metabolic syndrome. Adv. Exp. Med. Biol. 960, 1-17. doi: 10.1007/978-3-319-48382-5_1

Escobedo, N., and Oliver, G. (2017). The lymphatic vasculature: its role in adipose metabolism and obesity. Cell Metab. 26, 598-609.

Escobedo, N., Proulx, S. T., Karaman, S., Dillard, M. E., Johnson, N., Detmar, M., et al. (2016). Restoration of lymphatic function rescues obesity in Prox1haploinsufficient mice. JCI Insight 1:e85096. doi: 10.1172/jci.insight.85096

Esser, N., Legrand-Poels, S., Piette, J., Scheen, A. J., and Paquot, N. (2014). Inflammation as a link between obesity, metabolic syndrome and type 2 diabetes. Diabetes Res. Clin. Pract. 105, 141-150. doi: 10.1016/j.diabres.2014.04. 006

Fang, J., Dagenais, S. L., Erickson, R. P., Arlt, M. F., Glynn, M. W., Gorski, J. L., et al. (2000). Mutations in FOXC2 (MFH-1), a forkhead family transcription factor, are responsible for the hereditary lymphedema-distichiasis syndrome. Am. J. Hum. Genet. 67, 1382-1388.

Fatima, A., Wang, Y., Uchida, Y., Norden, P., Liu, T., Culver, A., et al. (2016). Foxc1 and Foxc2 deletion causes abnormal lymphangiogenesis and correlates with ERK hyperactivation. J. Clin. Invest. 126, 2437-2451.

Förstermann, U., and Sessa, W. C. (2012). Nitric oxide synthases: regulation and function. 33, 829-837; 837a-837d.

Franceschini, N., Almasy, L., MacCluer, J. W., Goring, H. H., Cole, S. A., Diego, V. P., et al. (2008). Diabetes-specific genetic effects on obesity traits in American Indian populations: the Strong Heart Family Study. BMC Med. Genet. 9:90. doi: 10.1186/1471-2350-9-90

García Nores, G. D., Cuzzone, D. A., Albano, N. J., Hespe, G. E., Kataru, R. P., Torrisi, J. S., et al. (2016). Obesity but not high-fat diet impairs lymphatic function. Int. J. Obes. 40, 1582-1590. doi: 10.1038/ijo.2016.96

García-Caballero, M., Zecchin, A., Souffreau, J., Truong, A.-C. K., Teuwen, L.-A., Vermaelen, W., et al. (2019). Role and therapeutic potential of dietary ketone bodies in lymph vessel growth. Nat. Metabol. 1, 666-675. doi: 10.1038/s42255019-0087-y

Gashev, A. A., Davis, M. J., and Zawieja, D. C. (2002). Inhibition of the active lymph pump by flow in rat mesenteric lymphatics and thoracic duct. J. Physiol. 540(Pt 3), 1023-1037.

Gasheva, O. Y., Zawieja, D. C., and Gashev, A. A. (2006). Contraction-initiated NOdependent lymphatic relaxation: a self-regulatory mechanism in rat thoracic duct. J. Physiol. 575(Pt 3), 821-832.

Goffman, T. E., Laronga, C., Wilson, L., and Elkins, D. (2004). Lymphedema of the arm and breast in irradiated breast cancer patients: risks in an era of dramatically changing axillary surgery. Breast J. 10, 405-411. doi: 10.1111/j. 1075-122X.2004.21411.x

Gomez-Ambrosi, J., Catalan, V., Rodriguez, A., Ramirez, B., Silva, C., Gil, M. J., et al. (2010). Involvement of serum vascular endothelial growth factor family 
members in the development of obesity in mice and humans. J. Nutr. Biochem. 21, 774-780. doi: 10.1016/j.jnutbio.2009.05.004

Greene, A. K., Grant, F. D., and Slavin, S. A. (2012). Lower-extremity lymphedema and elevated body-mass index. N. Engl. J. Med. 366, 2136-2137. doi: 10.1056/ NEJMc1201684

Grundy, S. M. (2004). Obesity, metabolic syndrome, and cardiovascular disease. J. Clin. Endocrinol. Metab. 89, 2595-2600. doi: 10.1210/jc.2004-0372

Haffner, S., Temprosa, M., Crandall, J., Fowler, S., Goldberg, R., Horton, E., et al. (2005). Intensive lifestyle intervention or metformin on inflammation and coagulation in participants with impaired glucose tolerance. Diabetes 54, 1566-1572.

Hamet, P., Haloui, M., Harvey, F., Marois-Blanchet, F. C., Sylvestre, M. P., Tahir, M. R., et al. (2017). PROX1 gene CC genotype as a major determinant of early onset of type 2 diabetes in slavic study participants from action in diabetes and vascular disease: preterax and diamicron MR controlled evaluation study. J. Hypertens. 35, S24-S32.

Harvey, N. L. (2008). The Link between Lymphatic Function and Adipose Biology. Ann. N. Y. Acad. Sci. 1131, 82-88. doi: 10.1196/annals.1413.007

Harvey, N. L., Srinivasan, R. S., Dillard, M. E., Johnson, N. C., Witte, M. H., Boyd, K., et al. (2005). Lymphatic vascular defects promoted by Prox1 haploinsufficiency cause adult-onset obesity. Nat. Genet. 37, 1072-1081. doi: $10.1038 /$ ng1642

Helyer, L. K., Varnic, M., Le, L. W., Leong, W., and McCready, D. (2010). Obesity is a risk factor for developing postoperative lymphedema in breast cancer patients. Breast J. 16, 48-54. doi: 10.1111/j.1524-4741.2009.00855.x

Hespe, G. E., Kataru, R. P., Savetsky, I. L., Garcia Nores, G. D., Torrisi, J. S., Nitti, M. D., et al. (2016). Exercise training improves obesity-related lymphatic dysfunction. J. Physiol. 594, 4267-4282. doi: 10.1113/JP271757

Horra, A., Salazar, J., Ferre, R., Vallve, J. C., Guardiola, M., Rosales, R., et al. (2009). Prox-1 and FOXC2 gene expression in adipose tissue: a potential contributory role of the lymphatic system to familial combined hyperlipidaemia. Atherosclerosis 206, 343-345. doi: 10.1016/j.atherosclerosis. 2009.02.026

Hruby, A., and Hu, F. B. (2015). The epidemiology of obesity: a big picture. PharmacoEconomics 33, 673-689. doi: 10.1007/s40273-014-0243-x.13/

Johansson, K., Ohlsson, K., Ingvar, C., Albertsson, M., and Ekdahl, C. (2002). Factors associated with the development of arm lymphedema following breast cancer treatment: a match pair case-control study. Lymphology 35, 59-71.

Karaman, S., Hollmen, M., Robciuc, M. R., Alitalo, A., Nurmi, H., Morf, B., et al. (2015). Blockade of VEGF-C and VEGF-D modulates adipose tissue inflammation and improves metabolic parameters under high-fat diet. Mol. Metab. 4, 93-105. doi: 10.1016/j.molmet.2014.11.006

Karaman, S., Hollmen, M., Yoon, S. Y., Alkan, H. F., Alitalo, K., Wolfrum, C., et al. (2016). Transgenic overexpression of VEGF-C induces weight gain and insulin resistance in mice. Sci. Rep. 6:31566. doi: 10.1038/srep31566

Karaman, S., Leppanen, V. M., and Alitalo, K. (2018). Vascular endothelial growth factor signaling in development and disease. Development 145:dev151019. doi: 10.1242/dev.151019

Karkkainen, M. J., Haiko, P., Sainio, K., Partanen, J., Taipale, J., Petrova, T. V., et al. (2004). Vascular endothelial growth factor $C$ is required for sprouting of the first lymphatic vessels from embryonic veins. Nat. Immunol. 5, 74-80. doi: $10.1038 /$ ni1013

Karkkainen, M. J., Saaristo, A., Jussila, L., Karila, K. A., Lawrence, E. C., Pajusola, K., et al. (2001). A model for gene therapy of human hereditary lymphedema. Proc. Natl. Acad. Sci. U.S.A. 98:12677. doi: 10.1073/pnas.221449198

Karpanen, T., Wirzenius, M., Makinen, T., Veikkola, T., Haisma, H. J., Achen, M. G., et al. (2006). Lymphangiogenic growth factor responsiveness is modulated by postnatal lymphatic vessel maturation. Am. J. Pathol. 169, 708718.

Kataru, R. P., Baik, J. E., Park, H. J., Wiser, I., Rehal, S., Shin, J. Y., et al. (2019). Regulation of immune function by the lymphatic system in lymphedema. Front. Immunol. 10:470. doi: 10.3389/fimmu.2019.00470

Kataru, R. P., Jung, K., Jang, C., Yang, H., Schwendener, R. A., Baik, J. E., et al. (2009). Critical role of CD11b+ macrophages and VEGF in inflammatory lymphangiogenesis, antigen clearance, and inflammation resolution. Blood 113, 5650-5659. doi: 10.1182/blood-2008-09-176776
Kataru, R. P., Kim, H., Jang, C., Choi, D. K., Koh, B. I., Kim, M., et al. (2011). $\mathrm{T}$ lymphocytes negatively regulate lymph node lymphatic vessel formation. Immunity 34, 96-107. doi: 10.1016/j.immuni.2010.12.016

Kazenwadel, J., and Harvey, N. L. (2016). Morphogenesis of the lymphatic vasculature: a focus on new progenitors and cellular mechanisms important for constructing lymphatic vessels. Dev. Dynam. 245, 209-219. doi: 10.1002/dvdy. 24313

Keith, L., Rowsemitt, C., and Richards, L. G. (2017). Lifestyle modification group for lymphedema and obesity results in significant health outcomes. Am. J. Lifestyle Med. doi: 10.1177/1559827617742108

Kennedy, A. R., Pissios, P., Otu, H., Roberson, R., Xue, B., Asakura, K., et al. (2007). A high-fat, ketogenic diet induces a unique metabolic state in mice. Am. J. Physiol. Endocrinol. Metab. 292, E1724-E1739. doi: 10.1152/ajpendo.00717. 2006

Kim, H., Kataru, R. P., and Koh, G. Y. (2014). Inflammation-associated lymphangiogenesis: a double-edged sword? J. Clin. Invest. 124, 936-942.

Kim, H. J., Yoo, Y. J., Ju, Y. S., Lee, S., Cho, S. I., Sung, J., et al. (2013). Combined linkage and association analyses identify a novel locus for obesity near PROX1 in Asians. Obesity (Silver Spring) 21, 2405-2412. doi: 10.1002/oby.20153

Kim, Y., Hwang, S. D., Lim, J. H., Kim, M. Y., Kim, E. N., Choi, B. S., et al. (2019). Attenuated lymphatic proliferation ameliorates diabetic nephropathy and highfat diet-induced renal lipotoxicity. Sci. Rep. 9:1994. doi: 10.1038/s41598-01838250-7

Klotz, L., Norman, S., Vieira, J. M., Masters, M., Rohling, M., Dube, K. N., et al. (2015). Cardiac lymphatics are heterogeneous in origin and respond to injury. Nature 522, 62-67.

Kobayashi, K., Forte, T. M., Taniguchi, S., Ishida, B. Y., Oka, K., and Chan, L. (2000). The $\mathrm{db} / \mathrm{db}$ mouse, a model for diabetic dyslipidemia: molecular characterization and effects of Western diet feeding. Metabolism 49, 22-31. doi: 10.1016/s0026-0495(00)90588-2

Koster, A., Stenholm, S., Alley, D. E., Kim, L. J., Simonsick, E. M., Kanaya, A. M., et al. (2010). Body fat distribution and inflammation among obese older adults with and without metabolic syndrome. Obesity (Silver Spring) 18, 2354-2361.

Kovacs, P., Lehn-Stefan, A., Stumvoll, M., Bogardus, C., and Baier, L. J. (2003). Genetic variation in the human winged helix/forkhead transcription factor gene FOXC2 in Pima Indians. Diabetes 52, 1292-1295. doi: 10.2337/diabetes.52.5. 1292

Kretowski, A., Adamska, E., Maliszewska, K., Wawrusiewicz-Kurylonek, N., Citko, A., Goscik, J., et al. (2015). The rs340874 PROX1 type 2 diabetes mellitus risk variant is associated with visceral fat accumulation and alterations in postprandial glucose and lipid metabolism. Genes Nutr. 10:4

Kubes, P., and Granger, D. N. (1992). Nitric oxide modulates microvascular permeability. Am. J. Physiol. 262(2 Pt 2), H611-H615. doi: 10.1152/ajpheart. 1992.262.2.H611

Kubota, N., Terauchi, Y., Yamauchi, T., Kubota, T., Moroi, M., Matsui, J., et al. (2002). Disruption of adiponectin causes insulin resistance and neointimal formation. J. Biol. Chem. 277, 25863-25866. doi: 10.1074/jbc.C200251200

Lammoglia, G. M., Van Zandt, C. E., Galvan, D. X., Orozco, J. L., Dellinger, M. T., and Rutkowski, J. M. (2016). Hyperplasia, de novo lymphangiogenesis, and lymphatic regression in mice with tissue-specific, inducible overexpression of murine VEGF-D. Am. J. Physiol. Heart Circ Physiol. 311, H384-H394. doi: 10.1152/ajpheart.00208.2016

Leak, L. V., and Burke, J. F. (1968). Ultrastructural studies on the lymphatic anchoring filaments. J. Cell Biol. 36, 129-149.

Leak, L. V., Cadet, J. L., Griffin, C. P., and Richardson, K. (1995). Nitric oxide production by lymphatic endothelial cells in vitro. Biochem. Biophys. Res. Commun. 217, 96-105. doi: 10.1006/bbrc.1995.2750

Lecompte, S., Pasquetti, G., Hermant, X., Grenier-Boley, B., Gonzalez-Gross, M., De Henauw, S., et al. (2013). Genetic and molecular insights into the role of PROX1 in glucose metabolism. Diabetes 62, 1738-1745.

Lee, Y., Chakraborty, S., Meininger, C. J., and Muthuchamy, M. (2018). Insulin resistance disrupts cell integrity, mitochondrial function, and inflammatory signaling in lymphatic endothelium. Microcirculation 25:e12492. doi: 10.1111/ micc. 12492

Liao, S., Cheng, G., Conner, D. A., Huang, Y., Kucherlapati, R. S., Munn, L. L., et al. (2011). Impaired lymphatic contraction associated with immunosuppression. Proc. Natl. Acad. Sci. U.S.A. 108, 18784-18789. 
Lim, H. Y., Rutkowski, J. M., Helft, J., Reddy, S. T., Swartz, M. A., Randolph, G. J., et al. (2009). Hypercholesterolemic mice exhibit lymphatic vessel dysfunction and degeneration. Am. J. Pathol. 175, 1328-1337. doi: 10.2353/ajpath.2009. 080963

Lim, H. Y., Thiam, C. H., Yeo, K. P., Bisoendial, R., Hii, C. S., McGrath, K. C., et al. (2013). Lymphatic vessels are essential for the removal of cholesterol from peripheral tissues by SR-BI-mediated transport of HDL. Cell Metab. 17, 671-684. doi: 10.1016/j.cmet.2013.04.002

Lin, C. T., Ou, K. W., and Chang, S. C. (2013). Diabetic foot ulcers combination with lower limb lymphedema treated by staged charles procedure: case report and literature review. Pak. J. Med. Sci. 29, 1062-1064.

Liu, X., Pasula, S., Song, H., Tessneer, K. L., Dong, Y., Hahn, S., et al. (2014). Temporal and spatial regulation of epsin abundance and VEGFR3 signaling are required for lymphatic valve formation and function. Sci. Signal. 7:ra97.

Lo Sasso, G., Schlage, W. K., Boue, S., Veljkovic, E., Peitsch, M. C., and Hoeng, J. (2016). The Apoe(-/-) mouse model: a suitable model to study cardiovascular and respiratory diseases in the context of cigarette smoke exposure and harm reduction. J. Transl. Med. 14:146.

Lohrmann, C., Foeldi, E., and Langer, M. (2009). MR imaging of the lymphatic system in patients with lipedema and lipo-lymphedema. Microvasc. Res. 77, 335-339. doi: 10.1016/j.mvr.2009.01.005

Lumeng, C. N., Bodzin, J. L., and Saltiel, A. R. (2007). Obesity induces a phenotypic switch in adipose tissue macrophage polarization. J. Clin. Invest. 117, 175-184.

Lumeng, C. N., and Saltiel, A. R. (2011). Inflammatory links between obesity and metabolic disease. J. Clin. Invest. 121, 2111-2117.

Ma, W., and Oliver, G. (2017). Lymphatic endothelial cell plasticity in development and disease. Physiology (Bethesda) 32, 444-452.

Makinen, T., Jussila, L., Veikkola, T., Karpanen, T., Kettunen, M. I., Pulkkanen, K. J., et al. (2001). Inhibition of lymphangiogenesis with resulting lymphedema in transgenic mice expressing soluble VEGF receptor-3. Nat. Med. 7, 199-205. doi: $10.1038 / 84651$

Mansour, S., Connell, F., Steward, C., Ostergaard, P., Brice, G., Smithson, S., et al. (2010). Emberger syndrome-primary lymphedema with myelodysplasia: report of seven new cases. Am. J. Med. Genet. A 152A, 2287-2296. doi: 10.1002/ajmg. a. 33445

Marques, S. M., Campos, P. P., Castro, P. R., Cardoso, C. C., Ferreira, M. A., and Andrade, S. P. (2011). Genetic background determines mouse strain differences in inflammatory angiogenesis. Microvasc. Res. 82, 246-252. doi: 10.1016/j.mvr. 2011.08.011

Martel, C., Li, W., Fulp, B., Platt, A. M., Gautier, E. L., Westerterp, M., et al. (2013). Lymphatic vasculature mediates macrophage reverse cholesterol transport in mice. J Clin. Investig. 123, 1571-1579.

Martinez-Corral, I., Ulvmar, M. H., Stanczuk, L., Tatin, F., Kizhatil, K., John, S. W., et al. (2015). Nonvenous origin of dermal lymphatic vasculature. Circ. Res. 116, 1649-1654. doi: 10.1161/circresaha.116.306170

Martin-Murphy, B. V., You, Q., Wang, H., De La Houssaye, B. A., Reilly, T. P., Friedman, J. E., et al. (2014). Mice lacking natural killer $\mathrm{T}$ cells are more susceptible to metabolic alterations following high fat diet feeding. PLoS ONE 9:e80949. doi: 10.1371/journal.pone.0080949

McGettigan, B., McMahan, R., Orlicky, D., Burchill, M., Danhorn, T., Francis, P., et al. (2019). Dietary lipids differentially shape nonalcoholic steatohepatitis progression and the transcriptome of kupffer cells and infiltrating macrophages. Hepatology 70, 67-83.

McLaughlin, S. A., Wright, M. J., Morris, K. T., Giron, G. L., Sampson, M. R., Brockway, J. P., et al. (2008). Prevalence of lymphedema in women with breast cancer 5 years after sentinel lymph node biopsy or axillary dissection: objective measurements. J. Clin. Oncol. 26, 5213-5219.

Meek, A. G. (1998). Breast radiotherapy and lymphedema. Cancer 83, 2788-2797.

Mehrara, B. J., and Greene, A. K. (2014). Lymphedema and obesity: is there a link? Plast Reconstr. Surg. 134, 154e-160e.

Meric, F., Buchholz, T. A., Mirza, N. Q., Vlastos, G., Ames, F. C., Ross, M. I., et al. (2002). Long-term complications associated with breast-conservation surgery and radiotherapy. Ann. Surg. Oncol. 9, 543-549. doi: 10.1007/bf025 73889

Milasan, A., Smaani, A., and Martel, C. (2019). Early rescue of lymphatic function limits atherosclerosis progression in $\mathrm{Ldlr}(-/-)$ mice. Atherosclerosis 283, 106119. doi: 10.1016/j.atherosclerosis.2019.01.031
Mittendorfer, B. (2011). Origins of metabolic complications in obesity: adipose tissue and free fatty acid trafficking. Curr. Opin. Clin. Nutr. Metab Care 14, 535-541.

Muthuchamy, M., Gashev, A., Boswell, N., Dawson, N., and Zawieja, D. (2003). Molecular and functional analyses of the contractile apparatus in lymphatic muscle. FASEB J. 17, 920-922. doi: 10.1096/fj.02-0626fje

Nilsson, J., Ericsson, M., Joibari, M. M., Anderson, F., Carlsson, L., Nilsson, S. K., et al. (2016). A low-carbohydrate high-fat diet decreases lean mass and impairs cardiac function in pair-fed female C57BL/6J mice. Nutr. Metab. (Lond.) 13:79.

Nitti, M. D., Hespe, G. E., Kataru, R. P., Garcia Nores, G. D., Savetsky, I. L., Torrisi, J. S., et al. (2016). Obesity-induced lymphatic dysfunction is reversible with weight loss. J. Physiol. 594. 7073-7087. doi: 10.1113/JP273061

Norrmen, C., Ivanov, K. I., Cheng, J., Zangger, N., Delorenzi, M., Jaquet, M., et al. (2009). FOXC2 controls formation and maturation of lymphatic collecting vessels through cooperation with NFATc1. J. Cell Biol. 185, 439-457.

Nurmi, H., Saharinen, P., Zarkada, G., Zheng, W., Robciuc, M. R., and Alitalo, K. (2015). VEGF-C is required for intestinal lymphatic vessel maintenance and lipid absorption. EMBO Mol. Med. 7, 1418-1425. doi: 10.15252/emmm. 201505731

Oka, M., Iwata, C., Suzuki, H. I., Kiyono, K., Morishita, Y., Watabe, T., et al. (2008). Inhibition of endogenous TGF-beta signaling enhances lymphangiogenesis. Blood 111, 4571-4579. doi: 10.1182/blood-2007-10-120337

O’Neill, S., and O'Driscoll, L. (2015). Metabolic syndrome: a closer look at the growing epidemic and its associated pathologies. Obes. Rev. 16, 1-12. doi: 10.1111/obr.12229

Ortega, F. B., Lavie, C. J., and Blair, S. N. (2016). Obesity and cardiovascular disease. Circ. Res. 118, 1752-1770. doi: 10.1161/circresaha.115.306883

Ostergaard, P., Simpson, M. A., Connell, F. C., Steward, C. G., Brice, G., Woollard, W. J., et al. (2011). Mutations in GATA2 cause primary lymphedema associated with a predisposition to acute myeloid leukemia (Emberger syndrome). Nat. Genet. 43, 929-931. doi: 10.1038/ng.923

Ozaslan, C., and Kuru, B. (2004). Lymphedema after treatment of breast cancer. Am. J. Surg. 187, 69-72. doi: 10.1016/j.amjsurg.2002.12.003

Paquet-Fifield, S., Levy, S. M., Sato, T., Shayan, R., Karnezis, T., Davydova, N., et al. (2013). Vascular endothelial growth factor-d modulates caliber and function of initial lymphatics in the dermis. J. Invest. Dermatol. 133, 2074-2084. doi: 10.1038/jid.2013.83

Paskett, E. D., Dean, J. A., Oliveri, J. M., and Harrop, J. P. (2012). Cancer-related lymphedema risk factors, diagnosis, treatment, and impact: a review. J. Clin. Oncol. 30, 3726-3733. doi: 10.1200/JCO.2012.41.8574

Petrek, J. A., Senie, R. T., Peters, M., and Rosen, P. P. (2001). Lymphedema in a cohort of breast carcinoma survivors 20 years after diagnosis. Cancer 92, 1368-1377.

Pickup, J. C., Mattock, M. B., Chusney, G. D., and Burt, D. (1997). NIDDM as a disease of the innate immune system: association of acute-phase reactants and interleukin-6 with metabolic syndrome X. Diabetologia 40, 1286-1292. doi: $10.1007 / \mathrm{s} 001250050822$

Puchalska, P., and Crawford, P. A. (2017). Multi-dimensional roles of ketone bodies in fuel metabolism, signaling, and therapeutics. Cell Metab. 25, 262-284.

Rahier, J. F., De Beauce, S., Dubuquoy, L., Erdual, E., Colombel, J. F., Jouret-Mourin, A., et al. (2011). Increased lymphatic vessel density and lymphangiogenesis in inflammatory bowel disease. Aliment Pharmacol. Ther. 34, 533-543. doi: 10.1111/j.1365-2036.2011.04759.x

Rajnoch, C., Ferguson, S., Metcalfe, A. D., Herrick, S. E., Willis, H. S., and Ferguson, M. W. (2003). Regeneration of the ear after wounding in different mouse strains is dependent on the severity of wound trauma. Dev. Dyn. 226, 388-397. doi: $10.1002 /$ dvdy.10242

Randolph, G. J., Ivanov, S., Zinselmeyer, B. H., and Scallan, J. P. (2017). The lymphatic system: integral roles in immunity. Annu. Rev. Immunol. 35, 31-52. doi: 10.1146/annurev-immunol-041015-055354

Rasmussen, J. C., Herbst, K. L., Aldrich, M. B., Darne, C. D., Tan, I. C., Zhu, B., et al. (2014). An abnormal lymphatic phenotype is associated with subcutaneous adipose tissue deposits in Dercum's disease. Obesity (Silver Spring) 22, 21862192.

Regenfuss, B., Onderka, J., Bock, F., Hos, D., Maruyama, K., and Cursiefen, C. (2010). Genetic heterogeneity of lymphangiogenesis in different mouse strains. Am. J. Pathol. 177, 501-510. 
Ruddle, N. H., and Akirav, E. M. (2009). Secondary lymphoid organs: responding to genetic and environmental cues in ontogeny and the immune response. J. Immunol. 183, 2205-2212.

Rupnick, M. A., Panigrahy, D., Zhang, C. Y., Dallabrida, S. M., Lowell, B. B., Langer, R., et al. (2002). Adipose tissue mass can be regulated through the vasculature. Proc. Natl. Acad. Sci. U.S.A. 99, 10730-10735.

Rutkowski, J. M., Davis, K. E., and Scherer, P. E. (2009). Mechanisms of obesity and related pathologies: the macro- and microcirculation of adipose tissue. FEBS J. 276, 5738-5746. doi: 10.1111/j.1742-4658.2009.07303.x

Rutkowski, J. M., Markhus, C. E., Gyenge, C. C., Alitalo, K., Wiig, H., and Swartz, M. A. (2010). Dermal collagen and lipid deposition correlate with tissue swelling and hydraulic conductivity in murine primary lymphedema. Am. J. Pathol. 176, 1122-1129.

Rutkowski, J. M., Moya, M., Johannes, J., Goldman, J., and Swartz, M. A. (2006). Secondary lymphedema in the mouse tail: lymphatic hyperplasia, VEGF-C upregulation, and the protective role of MMP-9. Microvasc. Res. 72, 161-171.

Ryan, M. J., Didion, S. P., Davis, D. R., Faraci, F. M., and Sigmund, C. D. (2002). Endothelial dysfunction and blood pressure variability in selected inbred mouse strains. Arterioscler. Thromb. Vasc. Biol. 22, 42-48. doi: 10.1161/hq0102.101098

Saaristo, A., Tammela, T., Farkkila, A., Karkkainen, M., Suominen, E., YlaHerttuala, S., et al. (2006). Vascular endothelial growth factor-C accelerates diabetic wound healing. Am. J. Pathol. 169, 1080-1087.

Sabine, A., Agalarov, Y., Maby-El Hajjami, H., Jaquet, M., Hagerling, R., Pollmann, C., et al. (2012). Mechanotransduction, PROX1, and FOXC2 cooperate to control connexin37 and calcineurin during lymphatic-valve formation. Dev. Cell 22, 430-445. doi: 10.1016/j.devcel.2011.12.020

Sabine, A., Bovay, E., Demir, C. S., Kimura, W., Jaquet, M., Agalarov, Y., et al. (2015). FOXC2 and fluid shear stress stabilize postnatal lymphatic vasculature. J. Clin. Invest. 125, 3861-3877.

Sabine, A., Saygili Demir, C., and Petrova, T. V. (2016). Endothelial cell responses to biomechanical forces in lymphatic vessels. Antioxid. Redox Signal 25, 451465. doi: 10.1089/ars.2016.6685

Saltiel, A. R., and Olefsky, J. M. (2017). Inflammatory mechanisms linking obesity and metabolic disease. J. Clin. Invest. 127, 1-4.

Santambrogio, L. (2018). The lymphatic fluid. Int. Rev. Cell Mol. Biol. 337, 111-133. doi: 10.1016/bs.ircmb.2017.12.002

Savetsky, I. L., Albano, N. J., Cuzzone, D. A., Gardenier, J. C., Torrisi, J. S., Garcia Nores, G. D., et al. (2015a). Lymphatic function regulates contact hypersensitivity dermatitis in obesity. J. Invest. Dermatol. 135, 2742-2752. doi: 10.1038/jid.2015.283

Savetsky, I. L., Ghanta, S., Gardenier, J. C., Torrisi, J. S., Garcia Nores, G. D., Hespe, G. E., et al. (2015b). Th2 cytokines inhibit lymphangiogenesis. PLoS ONE 10:e0126908. doi: 10.1371/journal.pone.0126908

Savetsky, I. L., Torrisi, J. S., Cuzzone, D. A., Ghanta, S., Albano, N. J., Gardenier, J. C., et al. (2014). Obesity increases inflammation and impairs lymphatic function in a mouse model of lymphedema. Am. J. Physiol. Heart Circul. Physiol. 307, H165-H172. doi: 10.1152/ajpheart.00244.2014

Sawane, M., Kajiya, K., Kidoya, H., Takagi, M., Muramatsu, F., and Takakura, N. (2013). Apelin inhibits diet-induced obesity by enhancing lymphatic and blood vessel integrity. Diabetes 62, 1970-1980.

Scallan, J. P., Hill, M. A., and Davis, M. J. (2015). Lymphatic vascular integrity is disrupted in type 2 diabetes due to impaired nitric oxide signalling. Cardiovasc. Res. 107, 89-97. doi: 10.1093/cvr/cvv117

Scallan, J. P., Zawieja, S. D., Castorena-Gonzalez, J. A., and Davis, M. J. (2016). Lymphatic pumping: mechanics, mechanisms and malfunction. J. Physiol. 594, 5749-5768. doi: 10.1113/JP272088

Schaverien, M. V., Munnoch, D. A., and Brorson, H. (2018). Liposuction treatment of lymphedema. Semin. Plast Surg. 32, 42-47.

Schmid-Schonbein, G. W. (2003). The second valve system in lymphatics. Lymphat Res. Biol. 1, 25-29; discussion 29-31. doi: 10.1089/15396850360495664

Schoppmann, S. F., Birner, P., Stockl, J., Kalt, R., Ullrich, R., Caucig, C., et al. (2002). Tumor-associated macrophages express lymphatic endothelial growth factors and are related to peritumoral lymphangiogenesis. Am. J. Pathol. 161, 947-956.

Schulte-Merker, S., Sabine, A., and Petrova, T. V. (2011). Lymphatic vascular morphogenesis in development, physiology, and disease. J. Cell Biol. 193, $607-618$.
Schwager, S., Renner, S., Hemmerle, T., Karaman, S., Proulx, S. T., Fetz, R., et al. (2018). Antibody-mediated delivery of VEGF-C potently reduces chronic skin inflammation. JCI Insight 3, e124850.

Sevick-Muraca, E. M., Kwon, S., and Rasmussen, J. C. (2014). Emerging lymphatic imaging technologies for mouse and man. J. Clin. Invest. 124, 905-914.

Shao, X., and Liu, C. (2006). Influence of IFN- alpha and IFN- gamma on lymphangiogenesis. J. Interferon Cytokine Res. 26, 568-574. doi: 10.1089/jir. 2006.26.568

Shimizu, Y., Shibata, R., Ishii, M., Ohashi, K., Kambara, T., Uemura, Y., et al. (2013). Adiponectin-mediated modulation of lymphatic vessel formation and lymphedema. J. Am. Heart Assoc. 2:e00438. doi: 10.1161/JAHA.113.000438

Shin, K., Kataru, R. P., Park, H. J., Kwon, B. I., Kim, T. W., Hong, Y. K., et al. (2015). TH2 cells and their cytokines regulate formation and function of lymphatic vessels. Nat. Commun. 6:6196. doi: 10.1038/ncomms7196

Silha, J. V., Krsek, M., Sucharda, P., and Murphy, L. J. (2005). Angiogenic factors are elevated in overweight and obese individuals. Int. J. Obes. (Lond.) 29, 1308-1314. doi: 10.1038/sj.ijo.0802987

Skobe, M., Hamberg, L. M., Hawighorst, T., Schirner, M., Wolf, G. L., Alitalo, K., et al. (2001a). Concurrent induction of lymphangiogenesis, angiogenesis, and macrophage recruitment by vascular endothelial growth factor-C in melanoma. Am. J. Pathol. 159, 893-903.

Skobe, M., Hawighorst, T., Jackson, D. G., Prevo, R., Janes, L., Velasco, P., et al. (2001b). Induction of tumor lymphangiogenesis by VEGF-C promotes breast cancer metastasis. Nat. Med. 7, 192-198. doi: 10.1038/84643

Snel, M., Jonker, J. T., Schoones, J., Lamb, H., de Roos, A., Pijl, H., et al. (2012). Ectopic fat and insulin resistance: pathophysiology and effect of diet and lifestyle interventions. Int. J. Endocrinol. 2012:983814.

Stanczuk, L., Martinez-Corral, I., Ulvmar, M. H., Zhang, Y., Lavina, B., Fruttiger, M., et al. (2015). cKit lineage hemogenic endothelium-derived cells contribute to mesenteric lymphatic vessels. Cell Rep. 10, 1708-1721. doi: 10.1016/j.celrep. 2015.02.026

Stepanova, O. I., Krylov, A. V., Lioudyno, V. I., and Kisseleva, E. P. (2007). Gene expression for VEGF-A, VEGF-C, and their receptors in murine lymphocytes and macrophages. Biochemistry (Mosc) 72, 1194-1198. doi: 10. 1134/s0006297907110041

Swenson, K. K., Nissen, M. J., Leach, J. W., and Post-White, J. (2009). Case-control study to evaluate predictors of lymphedema after breast cancer surgery. Oncol. Nurs. Forum 36, 185-193. doi: 10.1188/09.Onf.185-193

Tamburini, B. A. J., Finlon, J. M., Gillen, A. E., Kriss, M. S., Kent Riemondy, A., $\mathrm{Fu}$, R., et al. (2019). Chronic liver disease in humans causes expansion and differentiation of liver lymphatic endothelial cells. Front. Immunol. 10:1036. doi: 10.3389/fimmu.2019.01036

Tammela, T., and Alitalo, K. (2010). Lymphangiogenesis: molecular mechanisms and future promise. Cell 140, 460-476.

Tirronen, A., Vuorio, T., Kettunen, S., Hokkanen, K., Ramms, B., Niskanen, H., et al. (2018). Deletion of lymphangiogenic and angiogenic growth factor VEGF-D leads to severe hyperlipidemia and delayed clearance of chylomicron remnants. Arteriosc. Thromb. Vasc. Biol. 38, 2327-2337. doi: 10.1161/atvbaha. 118.311549

Torrisi, J. S., Hespe, G. E., Cuzzone, D. A., Savetsky, I. L., Nitti, M. D., Gardenier, J. C., et al. (2016). Inhibition of inflammation and iNOS improves lymphatic function in obesity. Sci. Rep. 6:19817. doi: 10.1038/srep19817

Tsunemoto, H., Ikomi, F., and Ohhashi, T. (2003). Flow-mediated release of nitric oxide from lymphatic endothelial cells of pressurized canine thoracic duct. Jpn. J. Physiol. 53, 157-163. doi: 10.2170/jjphysiol.53.157

Vasileiou, A. M., Bull, R., Kitou, D., Alexiadou, K., Garvie, N. J., and Coppack, S. W. (2011). Oedema in obesity; role of structural lymphatic abnormalities. Int. J. Obes. (Lond.) 35, 1247-1250. doi: 10.1038/ijo.2010.273

von, der Weid, P. Y., Zhao, J., and Van Helden, D. F. (2001). Nitric oxide decreases pacemaker activity in lymphatic vessels of guinea pig mesentery. Am. J. Physiol. Heart Circ. Physiol. 280, H2707-H2716. doi: 10.1152/ajpheart.2001. 280.6.H2707

Wada, H., Ura, S., Kitaoka, S., Satoh-Asahara, N., Horie, T., Ono, K., et al. (2011). Distinct characteristics of circulating vascular endothelial growth factor-A and C levels in human subjects. PLoS ONE 6:e29351. doi: 10.1371/journal.pone. 0029351 
Walenbergh, S. M., Koek, G. H., Bieghs, V., and Shiri-Sverdlov, R. (2013). Non-alcoholic steatohepatitis: the role of oxidized low-density lipoproteins. J. Hepatol. 58, 801-810. doi: 10.1016/j.jhep.2012.11.014

Wang, Y., Beydoun, M. A., Liang, L., Caballero, B., and Kumanyika, S. K. (2008). Will all Americans become overweight or obese? estimating the progression and cost of the US obesity epidemic. Obesity (Silver Spring) 16, 2323-2330. doi: 10.1038/oby.2008.351

Weitman, E. S., Aschen, S. Z., Farias-Eisner, G., Albano, N., Cuzzone, D. A., Ghanta, S., et al. (2013). Obesity impairs lymphatic fluid transport and dendritic cell migration to lymph nodes. PLoS ONE:e70703. doi: 10.1371/journal.pone. 0070703

Werner, R. S., McCormick, B., Petrek, J., Cox, L., Cirrincione, C., Gray, J. R., et al. (1991). Arm edema in conservatively managed breast cancer: obesity is a major predictive factor. Radiology 180, 177-184. doi: 10.1148/radiology.180.1.2052688

Wigle, J. T., Chowdhury, K., Gruss, P., and Oliver, G. (1999). Prox1 function is crucial for mouse lens-fibre elongation. Nat. Genet. 21, 318-322. doi: 10.1038/ 6844

Wigle, J. T., Harvey, N., Detmar, M., Lagutina, I., Grosveld, G., Gunn, M. D., et al. (2002). An essential role for Prox1 in the induction of the lymphatic endothelial cell phenotype. EMBO J. 21, 1505-1513.

Wigle, J. T., and Oliver, G. (1999). Prox 1 function is required for the development of the murine lymphatic system. Cell 98, 769-778. doi: 10.1016/s0092-8674(00) 81511-1

Wilke, L. G., McCall, L. M., Posther, K. E., Whitworth, P. W., Reintgen, D. S., Leitch, A. M., et al. (2006). Surgical complications associated with sentinel lymph node biopsy: results from a prospective international cooperative group trial. Ann. Surg. Oncol. 13, 491-500. doi: 10.1245/aso.2006.05.013

Winer, S., Chan, Y., Paltser, G., Truong, D., Tsui, H., Bahrami, J., et al. (2009). Normalization of obesity-associated insulin resistance through immunotherapy. Nat. Med. 15, 921-929.

Wong, B. W., Wang, X., Zecchin, A., Thienpont, B., Cornelissen, I., Kalucka, J., et al. (2016). The role of fatty acid $\beta$-oxidation in lymphangiogenesis. Nature 542:49. doi: $10.1038 /$ nature 21028

Wu, H., Rahman, H. N. A., Dong, Y., Liu, X., Lee, Y., Wen, A., et al. (2018). Epsin deficiency promotes lymphangiogenesis through regulation of VEGFR3 degradation in diabetes. J. Clin. Invest. 128, 4025-4043. doi: 10.1172/JCI96063

Yadav, H., Quijano, C., Kamaraju, A. K., Gavrilova, O., Malek, R., Chen, W., et al. (2011). Protection from obesity and diabetes by blockade of TGF-beta/Smad3 signaling. Cell Metab. 14, 67-79.

Yang, Y., and Oliver, G. (2014). Development of the mammalian lymphatic vasculature. J. Clin. Investig. 124, 888-897. doi: 10.1172/JCI71609

Yimin, Furumaki, H., Matsuoka, S., Sakurai, T., Kohanawa, M., Zhao, S., et al. (2012). A novel murine model for non-alcoholic steatohepatitis developed by combination of a high-fat diet and oxidized low-density lipoprotein. Lab. Invest 92, 265-281. doi: 10.1038/labinvest.2011.159
Yuan, S. Y. (2006). New insights into eNOS signaling in microvascular permeability. Am. J. Physiol. Heart Circ. Physiol. 291, H1029-H1031. doi: 10. 1152/ajpheart.00509.2006

Yudkin, J. S., Stehouwer, C. D., Emeis, J. J., and Coppack, S. W. (1999). C-reactive protein in healthy subjects: associations with obesity, insulin resistance, and endothelial dysfunction: a potential role for cytokines originating from adipose tissue? Arterioscler Thromb. Vasc. Biol. 19, 972-978. doi: 10.1161/01.atv.19.4. 972

Zampell, J. C., Aschen, S., Weitman, E. S., Yan, A., Elhadad, S., De Brot, M., et al. (2012a). Regulation of adipogenesis by lymphatic fluid stasis: part Adipogenesis. I., fibrosis, and inflammation. Plast Reconstr. Surg. 129, 825-834.

Zampell, J. C., Yan, A., Elhadad, S., Avraham, T., Weitman, E., and Mehrara, B. J. (2012b). CD4(+) cells regulate fibrosis and lymphangiogenesis in response to lymphatic fluid stasis. PLoS ONE 7:e49940. doi: 10.1371/journal.pone.0049940

Zawieja, D. C. (2009). Contractile physiology of lymphatics. Lymphat. Res. Biol. 7 , 87-96.

Zawieja, S. D., Gasheva, O., Zawieja, D. C., and Muthuchamy, M. (2016). Blunted flow-mediated responses and diminished nitric oxide synthase expression in lymphatic thoracic ducts of a rat model of metabolic syndrome. Am. J. Physiol. Heart Circ. Physiol. 310, H385-H393.

Zawieja, S. D., Wang, W., Wu, X., Nepiyushchikh, Z. V., Zawieja, D. C., and Muthuchamy, M. (2012). Impairments in the intrinsic contractility of mesenteric collecting lymphatics in a rat model of metabolic syndrome. Am. J. Physiol. Heart Circ. Physiol. 302, H643-H653.

Zhang, F., Zarkada, G., Han, J., Li, J., Dubrac, A., Ola, R., et al. (2018). Lacteal junction zippering protects against diet-induced obesity. Science 361, 599-603.

Zhang, Y., Lu, Y., Ma, L., Cao, X., Xiao, J., Chen, J., et al. (2014). Activation of vascular endothelial growth factor receptor-3 in macrophages restrains TLR4NF-kappaB signaling and protects against endotoxin shock. Immunity 40, 501-514. doi: 10.1016/j.immuni.2014.01.013

Zheng, W., Aspelund, A., and Alitalo, K. (2014). Lymphangiogenic factors, mechanisms, and applications. J. Clin. Investig. 124, 878-887. doi: 10.1172/ JCI71603

Conflict of Interest: The authors declare that the research was conducted in the absence of any commercial or financial relationships that could be construed as a potential conflict of interest.

Copyright (C) 2020 Norden and Kume. This is an open-access article distributed under the terms of the Creative Commons Attribution License (CC BY). The use, distribution or reproduction in other forums is permitted, provided the original author(s) and the copyright owner(s) are credited and that the original publication in this journal is cited, in accordance with accepted academic practice. No use, distribution or reproduction is permitted which does not comply with these terms. 